\title{
EL PRINCIPIO DE SUBORDINACIÓN COMO FUNDAMENTO DEL ESTADO CONSTITUCIONAL. SU REGULACIÓN EN ARGENTINA, BRASIL, COLOMBIA, ECUADOR Y MÉXICO
}

RAÚL GUSTAVO FERREYRA 
SUMARIO

I. REFERENCIAS INICIALES. II. MARCO TEÓRICO. III. LA CONSTITUCIÓN, CUARTO ELEMENTO DEL ESTADO. IV. LAS REGLAS CONSTITUCIONALES. IV.1 Primera regla: sobre la subordinación. IV.2 Segunda regla: sobre la variación. IV.3 Tercera regla: sobre la distinción de funciones. IV.4 Cuarta regla: sobre la acción. Derechos fundamentales. V. REGLA SOBRE LA SUBORDINACIÓN. V.1 Suma regla. V.2 Relación con el Derecho Inrernacional de los Derechos Humanos (DIDH). VI. FORMULACIÓN Y REPRESENTACIÓN NORMATIVA DE LA REGLA SOBRE LA SUBORDINACIÓN. VI.1 Estado argentino. VI.2 Estado brasileño. VI.3 Estado colombiano. VI.4 Estado ecuatoriano. VI.5 Estado mexicano. VII. COMENTARIOS FINALES. VIII. BIBLIOGRAFÍA. 


\title{
EL PRINCIPIO DE SUBORDINACIÓN COMO FUNDAMENTO DEL ESTADO CONSTITUCIONAL. SU REGULACIÓN EN ARGENTINA, BRASIL, COLOMBIA, ECUADOR Y MÉXICO ${ }^{1}$
}

\author{
RAÚL GUSTAVO FERREYRA²
}

\section{REFERENCIAS INICIALES}

Siempre con el objeto de facilitar la comprensión del lector y el juicio crítico, presentaré diez argumentaciones apodícticas.

Primera. «América Latina» posee una múltiple entidad étnica. Aquí no constituye preocupación la cuestión terminológica, aunque es cierto que unos la critican porque la consideran racista (impuesta por el sueño imperial de Napoleón III) y otros porque sostienen que no todos somos «latinos», y dicho apelativo deja fuera a los negros, a los indios, etc. Dado que se trata de una discusión abierta, en este escrito utilizo la expresión «América Latina» sin perjuicio de que cada uno la cambie como mejor le plazca ${ }^{3}$.

Segunda. «Ser latinoamericano» no es una cuestión difícil de discernir, puesto que en su amalgama étnica reside su riqueza ${ }^{4}$. Hay un ser humano latinoamericano que se va abriendo paso en la historia en permanente resistencia al

${ }^{1}$ Una versión de este Texto fue presentada al XXII Encuentro de profesores de la Asociación Argentina de Derecho Constitucional. PANEL N. ${ }^{\circ} 2$ : «El constitucionalismo latinoamericano», Facultad de Derecho, Universidad de Buenos Aires, 27-29 de agosto de 2015.

${ }^{2}$ Catedrático de Derecho Constitucional, Facultad de Derecho, Universidad de Buenos Aires. Doctor de la Universidad de Buenos Aires. Av. Figueroa Alcorta 2263 (C1425CKB) - Email: rgferreyra@gmail.com

3 Zaffaroni, E. Raúl, El Derecho latinoamericano en la fase superior del colonialismo, ob. cit., p. 3.

${ }^{4}$ Vargas Llosa, Mario, Diccionario de América Latina, ob. cit., pág.12. 
colonialismo, que le niega o retacea su dignidad de persona, en un territorio en que muchos millones de seres humanos interactúan y sincretizan sus cosmovisiones, que son expresión de todas las culturas sometidas y marginadas por el colonialismo en todo el planeta Tierra. ${ }^{5}$

Tercera. Su delimitación territorial, aunque pareciera relativamente sencilla, no se encuentra exenta de complejidad. Si acaso existiese acuerdo, se predicará que abarca más de veinte millones de kilómetros cuadrados de la superficie emergida en el planeta.

Cuarta. Recientemente se ha señalado que en la «distribución del PIB mundial en 2012» la participación de «América Latina» (calculada en miles de millones de euros) es del $9 \%$ (nueve por ciento), semejante al porcentaje de su población en la escala mundial. ${ }^{6}$

Quinta. La explicitación escrita de los enunciados que integran la totalidad del Derecho constitucional actualmente vigente en cada uno de los Estados de América Latina requeriría, para su correcta disposición, más de 2.000 páginas. Teniendo en cuenta la extensión impuesta por el presente evento académico para este «texto crítico valorativo», las pretensiones deberán limitarse, más allá de cualquier supuesta agudeza por parte del autor.

Sexta. Se entiende por «constitucionalismo» ${ }^{7}$ al ordenamiento jurídico de una comunidad política, que se concreta mediante una constitución escrita, cuya supremacía significa la subordinación a sus enunciados de todos los actos producidos por los poderes que integran el gobierno del Estado.

En consecuencia, el término «constitucionalismo» puede ser reservado para definir la combinación o conglomerado normativo y no normativo; en el caso, con significado idéntico a «Derecho constitucional». Por «constitucionalismo» (o por «Derecho constitucional») se refiere al conjunto de disposiciones enunciadas tanto en el texto de la constitución como a las que, eventualmente, se encuentran fuera de su texto, al provenir de fuentes internacionales y gozar de jerarquía constitucional. A esto debería sumarse la interpretación judicial que se les haya asociado como significado, a condición de que el propio orden lo instaure, modele y justifique.

Séptima. La doctrina que expongo intenta distinguir la normatividad ${ }^{8}$ de las constituciones y, acaso, si dicha materia resulta suficiente para caracterizar

5 Zaffaroni, E. Raúl, El Derecho latinoamericano en la fase superior del colonialismo, ob. cit., p. 6.

6 V. PiketTy, Thomas, El capital en el siglo XXI, ob. cit., pág. 78.

7 Ver, en sentido semejante, SÁnCHEZ Viamonte, Carlos, «Constitucionalismo», ob. cit., pág. 1041.

8 Entiéndase por «normatividad» que los principios y reglas constitucionales son, o bien directamente aplicables, o aplicables tras construir otras disposiciones jurídicas a partir de sus 
un determinado «modelo de Derecho». Se trata, desde luego, de una normatividad generada o creada, que no significa — ni mucho menos- conciliación con su propia y total realización. Todo el Derecho constitucional debería reunir y comprender la viabilidad de su propia realización, dado que la idealidad que jamás puede concretarse en la realidad no debería ser objeto de concreción normativa.

Hace una década nuestra dogmática se ha visto enriquecida con el aporte mediante el cual se señalaron diferencias entre los ámbitos del «Derecho constitucional comparado latinoamericano» y el del «Derecho constitucional latinoamericano» ${ }^{9}$. Así, se dijo que el primero tiene por objeto conocer el universo constitucional (constituciones, leyes, jurisprudencia y costumbres constitucionales) de los Estados de la región, sus aproximaciones y sus diferencias. Por su parte, el segundo comprende las instituciones, organismos, órganos y asociaciones supraestatales que los países han creado por intermedio de tratados, con-

prescripciones; principios y reglas, pues, colman dicha definición.

9 La integración de América Latina aparece en diversos enunciados constitucionales. Así, en la Constitución Política de Colombia de 1991, se dispone en su Preámbulo «... impulsar la integración de la comunidad latinoamericana...». Tiene cotización normativa específica en el art. 9:

De igual manera, la política exterior de Colombia se orientará hacia la integración latinoamericana y del Caribe. Dicha orientación se refuerza en el art. 227: «El Estado promoverá la integración económica, social y política con las demás naciones y especialmente, con los países de América Latina y del Caribe mediante la celebración de tratados que sobre bases de equidad, igualdad y reciprocidad, creen organismos supranacionales, inclusive para conformar una comunidad latinoamericana de naciones. La ley podrá establecer elecciones directas para la constitución del Parlamento Andino y del Parlamento Latinoamericano».

Por su parte, la Constituição da República Federativa do Brasil de 1988 también ha reglado aspectos del asunto; por ejemplo, en el art. 4, Parágrafo único: «A República Federativa do Brasil buscará a integração econômica, política, social e cultural dos povos da América Latina, visando à formação de uma comunidade latinoamericana de nações».

En la Argentina, la Constitución federal (en adelante CF) también ha seguido la línea apuntada. En efecto, a partir de 1994, se ha ordenado en el art. 75, inc. 24, emplazado dentro de las atribuciones del Congreso: «Aprobar tratados de integración que deleguen competencias y jurisdicción a organizaciones supraestatales en condiciones de reciprocidad e igualdad, y que respeten el orden democrático y los derechos humanos. Las normas dictadas en su consecuencia tienen jerarquía superior a las leyes. La aprobación de estos tratados con Estados de Latinoamérica requerirá la mayoría absoluta de la totalidad de los miembros de cada Cámara».

La Constitución de Ecuador la anuncia desde el Preámbulo: «Nosotras y Nosotros, el pueblo soberano del Ecuador (...) Decidimos construir (...) Un país democrático, comprometido con la integración latinoamericana — sueño de Bolívar y Alfaro—, la paz y la solidaridad con todos los pueblos de la tierra...». También destina el Capítulo tercero del Título VIII, en un frondoso art. 423, cuyo texto comienza con la siguiente fórmula: «La integración, en especial con los países de Latinoamérica y el Caribe será un objetivo estratégico del Estado». 
venios y acuerdos internacionales, y que se obligan a respetar. Una gran porción es Derecho comunitario con instituciones propias. En este amplio campo se encuentran esfuerzos de integración económica y también política; tribunales, cortes y parlamentos supranacionales, así como mecanismos de consulta en los más diversos aspectos y cuestiones ${ }^{10}$.

Octava. Esta contribución concentra su objeto en un pequeño fragmento del «Derecho constitucional comparado latinoamericano»: el «Derecho constitucional» de cinco Estados de América Latina:

- Argentina: por ser el sistema constitucional más antiguo en vigencia, si bien con rupturas y variaciones, desde 1853.

- Brasil: por ser el sistema constitucional que ordena el Estado con el territorio y la población más extensos, desde 1988.

- Colombia: en cuanto representa uno de los desafíos más importantes para la ordenación constitucional en la región, a partir de 1991, así como también por su integración entre Derecho constitucional y Derechos Humanos (en adelante DDHH).

- Ecuador: por su creación reciente con pretensiones de nuevo paradigma, en 2008.

- México: en cuanto inauguró un cambio de paradigma hacia el constitucionalismo social, en 1917.

Analizaré, concretamente, el modo de ordenar o subordinar impuesto por la constitución en cada uno de estos Estados. Quizá pueda achacarse insuficiencia de probabilidades en el criterio que rigió las previsiones, que a su vez provocaron las elecciones normativas; sin embargo, pese a que no pretendo axiomatizar, descreo que la selección sea azarosa.

Novena. El normal fluir de la inteligencia, su propia fisiología natural, exige la estipulación de un punto de partida para la investigación y, luego, la disertación. No pretendo ni mucho menos glorificar el ejercicio de la función narrativa al elegir los cinco Estados mencionados. Tampoco pretendo devaluar o desconocer las virtudes de los órdenes jurídicos que no pueden ser aquí descritos por las razones antedichas.

Décima. La lectura comprensiva de los textos examinados — precisamente en su sumatoria de principios y reglas- permite advertir la presencia de casi todas las piezas conceptuales o categorías básicas inventadas por el constitucio-

${ }^{10}$ V. Carpizo, Jorge, «Derecho constitucional latinoamericano y comparado», ob. cit., págs. 949-989. 
nalismo, excepto el sistema de gobierno parlamentario y la posibilidad de transferencia o cesión de competencias soberanas a instituciones interestatales con nivel semejante a la constitución. Por lo tanto, en la actualidad, por primera vez desde los días de la independencia del yugo colonial europeo, la creación y ordenación constitucional, en cada uno de estos países, exhibe el momento más rico de todo su desarrollo histórico.

A continuación, trazaré un camino inicial para establecer regularidades y rupturas, semejanzas y desemejanzas, en las formas de ordenación que estipulan las constituciones elegidas, cuyo objetivo se describe en la próxima sección.

El plan de labor es el siguiente. En la sección III introduzco la afirmación del marco teórico capital que se enlaza en este escrito. En la sección IV discierno sobre el componente constitucional y privilegio la captación de sus posibilidades de fundamentación a partir de su enfoque externo. En la sección $\mathrm{V}$ expongo los fundamentos constitucionales del Estado, de acuerdo a la tesis aquí promovida. En la sección VI examino la regla de subordinación. Finalmente, en la sección VII analizo en particular la «regla sobre la subordinación» y su representación normativa en los fundamentos de los Estados escogidos. Por último, en la sección VIII realizo los comentarios finales.

\section{MARCO TEÓRICO}

La tesis pura o afirmación capital que engloba a este «texto de la sesión» es la siguiente: se denomina «Estado constitucional» ${ }^{11}$ a todo ente que congrega en su composición dos elementos constituyentes naturales (territorio y población) y dos elementos constituyentes no naturales (poder y constitución); uno de estos últimos es el «artificio fundamental», la regla suprema del orden estatal, cuya estabilidad y perdurabilidad se intenta establecer con hegemonía suficiente. En el Estado constitucional todo el Derecho del Estado debe ser Derecho genuinamente autorizado por la norma positiva fundamental de su orden coactivo.

La constitución es el fundamento (raíz) y fundamento (razón) que tiende a ordenar la vida del Estado. Estos dos fundamentos se despliegan u operan por intermedio de las cuatro reglas constitucionales «inacabadas» o principios constitucionales de «realización progresiva» que fundamentan al Estado: regla sobre la subordinación, regla sobre la variación, regla sobre la distinción y regla sobre la acción de los derechos fundamentales.

${ }^{11}$ Bonavides, Paulo, Curso de Direito constitucional, ob. cit. 


\section{LA CONSTITUCIÓN, CUARTO ELEMENTO DEL ESTADO}

La constitución no es un ente mundano aislado. Puede aislarse para su estudio dogmático; es decir, comprender, desde una perspectiva interna, su entidad y describir sus propiedades. Sin embargo, ella desempeña su tarea, con mayor o menor eficacia, con mayores o menores logros, dentro del ente estatal. Por consiguiente, también existe un enfoque externo: el propio modo en que la constitución se da, se presenta, se relaciona, en fin, reglamenta y fundamenta al mundo de los elementos del Estado; o el Estado a secas. Construir constitucionalmente al Estado no es tarea sencilla. Por eso, las orientaciones conceptuales sobre «organizarlo u ordenarlo» — siempre con rol fundamental- no son una mera cuestión de fe o de vocabulario: siempre se encuentran abiertas a delimitación y discusión crítica.

Los elementos del Estado siguen siendo el territorio, la población y el poder; sin embargo, tratándose de la arquitectura del poder y el deslinde entre autoridad y ciudadanía, con semejante sustantividad, la constitución se incorpora como cuarto y nuevo elemento al sistema. La concepción de la constitución como cuarto elemento significa un programa que se presenta — en la Argentina y, eventualmente, para América Latina, en pos de un nuevo modelo de integración real—y se intenta desarrollar paso a paso, porque no pretende privar de «fuerza expresiva» a la elemental trilogía de constituyentes del Estado ${ }^{12}$.

En principio, no debería existir otro «Estado» que no se encuentre «constituido» por la respectiva «constitución». No debería existir vida estatal fuera de la «constitución», pero existe. Aunque también se yergue un derecho estatal fuera de la constitución, aquí no hay espacio para su detallado tratamiento ${ }^{13}$.

\section{LAS REGLAS CONSTITUCIONALES}

Elegir al artificio constitucional como fundamento del Estado constituye una determinación política. Se adopta con antelación a la arquitectura estatal y se funde con sus fines. Por dicha razón, al desenvolverse la elección señalada se

12 V. HäBERLE, Peter, «La constitución en el contexto», ob. cit., pág. 225.

13 Para la evaluación de esta cuestión, se remite a Ferreyra, Raúl Gustavo: La constitución vulnerable. Crisis argentina y tensión interpretativa, Buenos Aires, Hammurabi, 2003 y también al ensayo «¿Tiempo constitucional? La constitución vulnerable», en www.infojus.gov.ar, 29/4/2014, Id Infojus: DACF140220. 
«opera» entre la decisión política y la propia arquitectura del sistema «una relación circular» que rige «toda la construcción» futura ${ }^{14}$.

El término «fundamento» se utiliza en varios sentidos y en múltiples contextos. Por amor a la claridad conceptual, entre la variopinta gama de significados, indico, a continuación, los elegidos. Así, «fundamento» en tanto «raíz» y «fundamento» en tanto «razón» son los senderos escogidos, en coincidencia con algunas de las alternativas lexicográficas. "Fundamentos constitucionales», en referencia a su raíz, porque toda la construcción jurídica de una comunidad, en determinado tiempo y espacio, queda o debe quedar sustentada, soportada, en fin, «fundamentada» por el propio Derecho que emana de la constitución, o cuya validación ésta autoriza. «Fundamentos constitucionales», en referencia a su razón, porque la validez jurídica de todo el Derecho de una comunidad, en determinado tiempo y espacio, queda o debe quedar explicada, justificada, en fin, «fundamentada» por el propio Derecho que emana de la constitución, o cuya validación ésta autoriza.

La fundamentación constitucional del Estado se cumple o puede cumplirse por intermedio de cuatro principios o reglas: subordinación, variación, distinción y acción. Ninguna de estas reglas o principios posee una realización absoluta; por eso son reglas «inacabadas» o reglas de realización progresiva, o reglas de realización relativa. Además, asumo en este texto que no existen diferencias ontológicas o estructurales entre los principios y las reglas que emanan de las normas constitucionales; las desemejanzas entre unos y otras son más bien de estilo, pese a que desde el punto de vista de la literatura jurídica, en general, se prefiere «regla». Bien entendido: que en toda obra literaria son esenciales el estilo y las ideas ${ }^{15}$.

Entonces, estos cuatro principios o reglas que emanan de la constitución pueden ser descritos como de terminación inacabada, porque por su intermedio se pretende fundamentar la regulación del Estado o la limitación de su inherente poder. En su etapa de fundamentación estatal cada uno de estos principios o reglas constitucionales se desenvuelve activamente, ya sea para configurar una raíz, o ya sea para justificar una razón. Son «materiales estructurales», «pilares»,

14 V. Zaffaroni, E. Raúl et al., Derecho penal, ob. cit., págs. 104-105.

${ }_{15}$ No asumo la distinción fuerte y débil, respectivamente, entre principios y reglas. Nótese: no significa que la distinción no posea entero fundamento; sólo es preciso señalar que tiene un alcance y contenido explicativo bastante más reducido del que comúnmente se le asocia, dado que la mayor parte de los principios tienden a comportarse como las reglas, porque también son «Derecho sobre Derecho», portadores de sana normatividad. Se sigue, en general, la consistente tesis de Luigi Ferrajoli, expuesta en «Constitucionalismo principialista y constitucionalismo garantista», ob. cit., págs. 11-50. 
o mejor, «elementos de la arquitectura del interior del Estado» emplazados de modo positivo, puestos en la constitución. Sin embargo, para mantener incólume el rigor analítico, prefiero agruparlos en dos órdenes, exactamente parejos a los «fundamentos constitucionales». Así, la regla sobre la variación o cambio y la regla sobre la subordinación caen dentro del marco de los fundamentos constitucionales observados como raíz. En cambio, la regla sobre la distinción y la regla sobre la acción se corresponden, o mejor dicho, son la manifestación de los fundamentos constitucionales apreciados, en este caso, como razón o justificación para el ejercicio de la fuerza estatal. Estos principios o reglas que surgen constitucionalmente observan el siguiente contenido.

\section{IV.1 Primera regla: sobre la subordinación}

Una de las definiciones fijadas por el Diccionario de la Real Academia Española sobre «subordinación» — «Sujeción a la orden, mando o dominio de alguien»- deja constancia semántica precisa de cuanto se discute. En efecto, en el «Estado constitucional», la subordinación del ente a la ordenación fundamental determinada por la constitución liga con decisión intransigente el propio concepto de Estado.

La regla sobre la subordinación jurídica del Estado por intermedio de cada uno de los despliegues que la constitución dispone (supremacía normativa, relación con el Derecho Internacional de los Derechos Humanos —en adelante DIDH - y control de constitucionalidad ${ }^{16}$ ) persigue establecer la certeza, es decir, el «conocimiento seguro» por parte de la ciudadanía y los servidores públicos sobre la determinación del campo dominado por el Derecho y del otro campo libre, un mundo sin reglas jurídicas. Los ciudadanos y los servidores públicos deben realizar el Derecho de la constitución.

\section{IV.2 Segunda regla: sobre la variación}

La constitución contiene una certidumbre: que su escritura metódica sólo podrá ser expandida, contraída o revisada, por el propio proceso detallado en su texto. Autoriza un solo lenguaje posible, por intermedio de un modelo autorre-

${ }^{16}$ Este mecanismo es una de las invenciones mayores para resguardar la rigurosa juridicidad y máxima subordinación del Estado al Derecho de la constitución; en otras palabras, resguardar la supremacía constitucional. Las limitaciones propias de este texto, insinuadas en la sección I, inhiben una posible descripción del sistema y sus elementos teóricos. Semejantes razones también impiden su descripción, más adelante, en el marco apropiado contemplado en la sección VII. 
ferente. El propio proceso de su cambio formaliza, sin temores, que la constitución puede ser reformada, con el debido respeto de sus determinaciones precisas, que nunca pueden ser entendidas como epístolas inútiles. De este modo, el artificio constitucional arraiga y afianza la estructura del Estado, al permitir el cambio de la regla suprema, que no es la copia ni imitación de ningún ente u objeto perfecto e ideal. Por eso corresponde habilitar la propia metamorfosis de la constitución. Me refiero al proceso real que cada orden jurídico regula y establece con sus propios matices, pero que en todos ellos participan los ciudadanos al elegir sus representantes y, en modo eventual, aprobar las normas elaboradas por el órgano constituyente, como así también la determinación de los órganos constitucionales y constituyentes determinados, de manera respectiva, para proceder a la variación normativa. Justificadamente, pues, la reforma configura un fundamento notable que sustenta la certeza en la edificación continua del orden jurídico del Estado.

\section{IV.3 Tercera regla: sobre la distinción de funciones}

Para construir un edificio es necesario que un arquitecto diseñe los planos; luego, que los obreros y los técnicos se ocupen materialmente de la edificación. Para escribir una novela o un mero relato resulta menester conocer la gramática o tener presente, acaso, que quienes lean el texto deben compartir el código escrito por el autor. Para construir y mantener jurídicamente a esa personalidad colectiva que se apoda «Estado», unos hombres tendrán que dar órdenes, encontrarse facultados para mandar con atribuciones suficientes, y otros deberán obedecerlas, ya sea por leal convicción, o por otro motivo que influya y determine el estado de dominación. El poder es el primer elemento no natural del Estado. Poder entendido como competencia atribuida a órganos del Estado en los que reside la capacidad para mandar o la facultad para dar órdenes, generar permisos o instalar prohibiciones. El poder es una cuestión fundamental en el Derecho de la constitución que ordena al Estado, con otra orientación, desde luego, pero con igual importancia que la libertad, que es la otra cuestión o materia fundamental.

La distinción de los poderes estatales — constituyentes y constituidos- tiene por inocultable finalidad contribuir a la consecución de lo que cotidianamente parece imposible, o digno de una de las más fantásticas de las utopías: someter el poder al cumplimiento de reglas de juego jurídicas preestablecidas. Se trata de impedir la concentración de los poderes. El fraccionamiento del poder del Estado constituye un formidable escudo de protección para la libertad de los habitantes. 


\section{IV.4 Cuarta regla: sobre la acción. Derechos fundamentales}

Hay constituciones que, en tanto fundamento de «soporte» y de «validez» de los sistemas jurídicos, no se limitan a programar un conjunto de procedimientos dirigidos a posibilitar la planificación y despliegue de la coerción a cargo de los poderes constituidos. Además, y aceptando que ellas no son fines sino medios, reputan que los derechos fundamentales en ellas insertados realizan una reglamentación que se considera el ámbito básico de la vida comunitaria en libertad, donde se les concibe no sólo como derechos subjetivos, sino también como reglas objetivas del sistema y, como tales, formal y no materialmente, líneas de acción que deben asegurar un uso correcto de la fuerza estatal. Desde luego, esta demarcación o determinación jamás puede ser completa. Resulta casi imposible que la constitución pueda determinar todas las orientaciones de su realización. En el Estado constitucional, la eliminación radical del ámbito de la discrecionalidad es insuperable; la discrecionalidad es un rasgo dominante de la especie humana.

En definitiva, los derechos fundamentales constituyen reglas o líneas significativas para la acción estatal y ciudadana.

\section{REGLA SOBRE LA SUBORDINACIÓN}

Derecho constitucional y Estado no son entidades equivalentes, pero sí inextricablemente vinculadas: el primero entraña una especial combinación de reglas; mientras que el segundo constituye una entidad de dominación y asociación de hombres asentados en un territorio determinado, con vocación de permanencia, cuya cabecera de la ordenación jurídica se encuentra ocupada, en general, por el Derecho emanado de la constitución. La relación necesaria que existe entre estos dos instrumentos o entidades debería ser, pues, que el concepto de constitución determinase, subordinase la noción de Estado.

Aunque no hay imágenes preparatorias, arraigar al Estado no coincide ni condice con su caída de rodillas. La auténtica subordinación del Estado al Derecho constitucional significa establecer una relación de dependencia entre los dos entes. Subordinar, en esta consideración jurídica, significa precisar argumentos que hagan factible que el Estado quede bajo la sujeción, a la orden, mando o dominio del Derecho que emana del sistema constitucional.

Una de las ideas aurorales desde fines del Siglo XVIII y comienzos del Siglo XIX ha sido la que postula la subordinación de los ciudadanos y los servidores públi- 
cos a una suma regla: la constitución ${ }^{17}$. Sin embargo, no hay relación entre la facilidad que existe para discurrir sobre las ventajas de dicha materia y la constante dificultad expuesta en su desventajosa realización concreta en cada comunidad estatal. Muchas veces, el propio orden constitucional pareciera en gradual desintegración o descomposición, excluido o descompensado por la energía repelente que emerge del desorden impuesto en determinadas comunidades estatales.

Sea como fuere, la constitución es el único «artificio fundamental» ${ }^{18}$ inventado, hasta el momento, para lograr cierta regulación, determinada limitación y específicos controles del poder del Estado. La determinación de reglas, fundantes y fijas, reguladoras del proceso político, constituye un acuerdo sustantivo para fundar la comunidad estatal y enraizar las convicciones de los ciudadanos y ciudadanas que integran su pueblo.

Me atrevo a justificar la proposición discutida sobre la subordinación jurídica del Estado, con marcado escepticismo. Apoyado en razonamientos anteriores y sin títulos excesivos, afirmo que, puesta la combinación de las reglas constitucionales en el mundo por el órgano habilitado para producirlas, o creadas por el órgano instituido para producirlas — siempre en representación de la ciudadanía-, sus «contenidos y procedimientos esenciales» ${ }^{19}$ permiten reconocer un modelo de Estado fundado en su correcta subordinación lógica al Derecho, hasta cierto punto. En este contexto, repito: todo el Estado se encuentra constituido por la constitución y todo el Derecho del Estado debe ser Derecho autorizado por la constitución. Existe una notable excepción, muchas veces gigantesca y no menos patética ni evidente: ciertos aspectos de la emergencia política, económica, social y financiera tienden a no calzar en la constitución. En dichas oportunidades se yergue un Derecho estatal fuera de la constitución, tal como ya he sugerido. Eliminar o reducir al estado policial —el tipo opuesto por antonomasia al Estado constitucional — no tiene que preocupar en la utilización de

${ }^{17}$ Observa Luigi Ferrajoli que existen diversas concepciones de la constitución y del constitucionalismo jurídico. Un rasgo común a todas ellas puede encontrarse en la idea de la subordinación de los poderes públicos — incluido el Legislativo- a una serie de normas superiores, que son las que en las actuales constituciones establecen derechos fundamentales (FERrajoli, Luigi: «Constitucionalismo garantista y constitucionalismo principialista», ob. cit., págs. 11-13). La afirmación resulta verdadera pero parcial, porque no basta con alcanzar el discurso de los poderes públicos. Tiene que contener, también, el ineludible deber de los ciudadanos de cumplir o acatar la constitución, cuyas estipulaciones normativas son el esquema para abarcar y contener las conductas alcanzadas por el Derecho.

18 Loewenstein, Karl, llama constitución al «dispositivo fundamental» para el control del proceso del poder (en Teoría de la constitución, ob. cit., págs.. 149-151).

19 V. HëBerle, Peter, El Estado constitucional, ob. cit., pág. 1. 
medios para lograrlo, porque la composición de este último destruye o devalúa la regla sobre la subordinación.

Asumido que el monopolio de la fuerza descansa en el Estado - y también la centralización jurídica-, se intenta racionalmente que las relaciones entre las personas y las de éstas con el Estado se desarrollen dentro de un orden de convivencia pacífica. Dependerá entonces vislumbrar si las determinaciones normativas se enlazan con la construcción de una sociedad de ciudadanos igualmente libres o si se enfatiza la traza de una mancomunidad de ciudadanos socialmente iguales o con cierta igualdad material de oportunidades. En otras palabras, el constitucionalismo liberal ha enfatizado en dar estabilidad y no empeorar las condiciones básicas; su carta de navegación, por tanto, descansa en un Estado respetuoso de la vida, de la libertad y de la dignidad. El constitucionalismo social introduce una variante singular, porque se edifica desde la perspectiva de un Estado promotor del desarrollo o mejoría de la condición humana; aquí, el proceso constituyente se orienta hacia el fomento y protección de la función de la propiedad, la educación, la salud, el trabajo, la familia, el ambiente y las riquezas naturales, entre otras categorías.

\section{V.1 Suma regla}

Los hombres han dedicado y destinado largos años a aprender y disfrutar de las ventajas que puede proporcionar, en general, una ordenación jurídica determinada; calificada por la primacía de una norma que se erige como superior, con jerarquía intransigente, indubitable e indisputable por encima del resto de las normas que integran el sistema jurídico estatal y se califican como inferiores. La configuración de reglas sobre Derecho constitucional ha contenido en su escritura - casi siempre - una regla suprema, es decir, la constitución como norma que fundamenta la totalidad del orden jurídico, «... tanto por su forma de creación, cuanto por su contenido» ${ }^{20}$.

Al idearse la primacía constitucional ${ }^{21}$ y su consecuente distinción jerárquica dentro del sistema, seguramente se infirió que con la formulación de unas

20 V. Bidart Campos, Germán J., El Derecho de la constitución y su fuerza normativa, ob. cit., pág. 92.

${ }^{21}$ Sobre la supremacía normativa de la constitución, el texto jurídico con mayor antigüedad y aún en vigor reside en la determinación establecida en el art. VI, Sección 2 de la Constitución de EE. UU. de 1787: «... Esta Constitución, y las leyes de los Estados Unidos que se expidan con arreglo a ella, y todos los tratados celebrados o que se celebren bajo la autoridad de los Estados Unidos, serán la suprema ley del país y los jueces de cada Estado estarán obligados a observarlos, a pesar de cualquier cosa en contrario que se encuentre en la Constitución o las leyes de cualquier 
pocas palabras se generaba una suma regla, cualidad que merece ser comprendida en sus justos alcances: «suprema, altísima y que no tiene superior» ${ }^{22}$.

Se emplaza una norma — la constitucional — en el sistema jurídico y se la posiciona como superior, porque ninguna será más alta que ella. Podría discutirse el don o gracia especial de la ubicuidad, es decir, si el emplazamiento y ulterior posicionamiento no constituyen, en rigor, una actuación autorreferencial de la propia norma constitucional que se autodetermina a sí misma. Nótese que la posición de la regla constitucional en el sistema e incluso su emplazamiento como suprema, aunque tiene el fundamento en ella misma, no implica contradicción lógica, porque manejar con cuidado los enunciados de naturaleza autorreferencial es algo bien distinto que predicar que todo enunciado de ese tipo o naturaleza carezca de significado. ${ }^{23}$ No hay misterio: para fundamentar la primacía de la regla constitucional, su cotización normativa descansa en su propio texto y no es preciso acudir a una norma superior a la constitución misma para resolver la cuestión. La supremacía se comprende en normas puestas en la propia escritura de la constitución; no hay ningún supuesto porque se trata de derecho constituyente puesto por el propio creador de la norma.

Significativamente, una constitución será el rodeo indeterminado de todas las circunstancias que atraviese en su realización, pese a que por definición constituya la suma regla sobre la pretendida ordenación previsible de la vida ciudadana insertada en la comunidad estatal. Entonces, cotizarla como «suma regla» significa indicar su inherente «supremacía normativa» ${ }^{24}$ o hacer referencia a su

Estado...». Basta pronunciar la fórmula normativa citada en voz alta para creer sobre la naturaleza todopoderosa de la suma regla, máxime al estimularse su judiciabilidad en el art. III, Sección 1: «Se depositará el poder judicial de los Estados Unidos en un Tribunal Supremo y en los tribunales inferiores que el Congreso instituya y establezca en lo sucesivo (...) Sección 2: El Poder Judicial entenderá en todas las controversias, tanto de derecho escrito como de equidad, que surjan como consecuencia de esta Constitución...».

22 Según DRAE, del latín summus.

${ }^{23}$ El delicado problema teórico sobre la autorreferencia en el Derecho constitucional ha sido estudiado y expuesto en FerReyra, Raúl Gustavo: Reforma constitucional y control de constitucionalidad. Limites a la judiciabilidad de la enmienda, Buenos Aires, Ediar, 2007, págs. 437-450. Se remite en homenaje a la brevedad. Aquí sólo se sugiere la bibliografía básica sobre la cuestión: Ross, Alf: (i) Sobre el Derecho y la justicia, Buenos Aires, Eudeba, 1994, págs. 80/82; (ii) «On Self Reference and Puzzle in Constitutional Law», en Mind, vol. 78, Issue 309, Oxford University Press, January 1969, p1/24; HART, H. L. A.: «Self-referring laws», en Essays in Jurisprudence and Philosophy, Oxford, Clarendon Press, 1985 (reprinting of the first edition 1983), págs. 170/178, publicado originariamente en obra en homenaje a Karl Olivecrona, 1964; y GuiBourG, Ricardo: «La autorreferencia normativa y la continuidad constitucional», en AA. VV.: El lenguaje del Derecho. Homenaje a Genaro R. Carrió, Buenos Aires, Abeledo Perrot, 1983, págs. 182/195; entre otros.

24 V. SAGüÉs, Néstor, Teoría de la constitución, ob. cit., págs. 98-99. 
significación más armoniosa como «teorema de la supremacía» ${ }^{25}$. «Supremacía» tiene semejante significado que «suma»: que no tiene superior en su línea, porque nada existe por encima de la regla fundamental del Estado.

El poder constituyente, integrado por los representantes de los ciudadanos que forman el pueblo del Estado, elabora y establece la norma constitucional, cuyo paso final, en ocasiones, también se remite a la aprobación del cuerpo electoral. En el momento constituyente de la creación jurídica originaria o en el momento constituyente de su variación, también se establecen las atribuciones para generar normas de rango inferior a la constitución. Desde luego, existirán en el ordenamiento normas de diverso rango y el único modo conocido para mantener la unidad del citado ordenamiento exigirá que todas las normas que lo componen se reduzcan a la «unidad» de criterio prescrito por la constitución. Esta reducción a la unidad será entera y coherentemente posible si y sólo si existe una norma de la cual deriven su normatividad, de modo directo o indirecto, todas las otras demás normas ${ }^{26}$.

La unidad del sistema jurídico estatal es una tarea fundamental que cumple la constitución, al subordinar la producción y la realización jurídica a una determinada graduación de jerarquías, procesos y contenidos, hasta cierto punto. La constitución, al configurar el parámetro de validación formal y material, determina la membresía de las reglas inferiores de todo el orden estatal.

El acuerdo básico de la ciudadanía significa, sin pompas, que en el escalonamiento jerárquico de las normas jurídicas, en principio, nada existe sobre la regla superior constitucional. Todo acto o norma producido o generado fuera del procedimiento o contenidos estipulados por la suma regla constitucional implica una «variación» no autorizada o cambio prohibido por el propio sistema; la transgresión genera una situación de disconformidad, un vicio o defecto: la inconstitucionalidad. La citada gradación jurídica ubica a todas las reglas en niveles diferentes; los mayores subordinan a los inferiores, y la constitución subordina a todo el orden jurídico del Estado. Así, puede postularse la unidad del ordenamiento jurídico del Estado. Sin hacer profecías, un historiador de las constituciones narraría, en el futuro Siglo XXII, que la «supremacía normativa», objetivada en la suma regla constitucional — inventada en el Siglo XVIII — fundamentó la unidad de los ordenamientos jurídicos estatales durante el Siglo XIX, mecanismo que se consolidó durante el Siglo XX y a comienzos del XXI constituía un solvente paradigma.

${ }^{25}$ V. EkmekdjIAn, Miguel Á., Tratado de Derecho constitucional, t. I, ob. cit., pág. 31.

${ }^{26}$ V. Boвbio, Norberto, Teoría general del Derecho, ob. cit., págs. 168-173. 


\section{V.2 Relación con el Derecho Inrernacional de los Derechos Humanos (DIDH)}

En nuestros Estados de América Latina, la redacción de la constitución dejó de ser una ficción o un estado de entes imaginarios a partir de la independencia de la sujeción colonial. Resulta inmensa la nómina de los modelos normativos proyectados en América Latina desde el siglo XIX ${ }^{27}$. Cientos de escritos que tuvieron diferentes senderos. Obras imperfectas, quizá tautológicas, porque el único modelo jurídico existente, por escrito y por entonces, era la Constitución de Estados Unidos, sancionada en Filadelfia en 1787. Aquí no ofreceré resumen ni comentario de estos textos. Constan en documentos reales, aunque muchas de ellas no pasaron del mero programa o tuvieron una vigencia muy breve. Sin embargo, en su lenguaje y en las derivaciones apropiadas de su lenguaje constitucional originario, precoz y parcamente, estipulaban la relación entre el «Derecho estatal»y el «Derecho internacional».

Concretamente, aquí se trata de la ubicación jurídica del DIDH en el orden jurídico del Estado constitucional y en determinado tiempo ${ }^{28}$, no sus modalidades de ingreso, progreso y egreso del sistema estatal.

En el parágrafo anterior se da cuenta de la primacía, revelada en el ámbito de subordinación del Estado al Derecho, al quedar ligada la validez de su orden jurídico al marco de referencia, formal y sustancial, tipificado y sostenido en la suma regla constitucional. La opción por una constitución escrita, cuya variación o cambio sólo debe formalizarse por procesos distintos a la producción de la ley ordinaria, establece un paradigma en el sistema de fuentes del orden jurídico. Entre los corolarios de dicha doctrina, hay una de relevante importancia teórica: por intermedio de la primacía constitucional los Estados intentaron diseñar, desarrollar y completar el monopolio de la fuerza, concretado en la regulación de la autoridad y la centralización terminante de los ámbitos vinculados con la producción y realización del Derecho, respectivamente.

Pronto se cumplirán 70 años desde la creación de la Organización de las Naciones Unidas (ONU), que, en rigor, como se ha observado ${ }^{29}$ por su natural competencia para la ordenación interestatal, debería llamarse «Estados Unidos». Uno de los datos más significativos de la ONU se objetiva en la normatividad producida a escala global, con profundos rasgos de derecho constituyente de la más alta estirpe sobre DDHH. Al leerse con seriedad, el artículo 1 de la Declaración Universal

27 V. Gargarella, Roberto, 200 años de constitucionalismo en América Latina 1810-2010, ob. cit.

${ }^{28}$ Bidart Campos, Germán J., Manual de la constitución reformada, ob. cit., pág. 371.

29 V. Bunge, Mario A., Filosofía política..., ob. cit., pág. 331. En este texto se añade que los EE. UU. deberían llamarse «Provincias Unidas». 
de los Derechos Humanos —aprobada por la Asamblea General el 10/12/1948 , en tanto proclama que «Todos los seres humanos nacen libres e iguales en dignidad y derechos y, dotados como están de razón y conciencia, deben comportarse fraternalmente los unos con los otros», llamará la atención que los hombres son una especie extremadamente original. Demoraron miles de años para escribir, con atisbos globales y determinada normatividad jurídica, que honrar la vida y «ayudar a vivir» ${ }^{30}$ con determinado régimen de bienestar ${ }^{31}$, no hacer daño ${ }^{32}$ al otro, «guiarse por el conocimiento» ${ }^{33}$ y ser solidario siempre que se pueda, en un marco de profundo e inmarcesible respeto al otro, constituye el repertorio fundamental para las bases mínimas del desarrollo de la vida de nuestra especie.

Deseo exaltar tres escenas, porque compendian, con buenas razones, aspectos relevantes de la relación del DIDH con el Derecho estatal.

Escena 1. El DIDH se produce en el ámbito de encuentros, debates, eventos, cónclaves o asambleas, siempre en sede internacional; siempre, por tanto, interestatal. Cambia, radicalmente, el paradigma del monopolio estatal en la creación del Derecho, aunque no cesa ni se devalúa la primacía constitucional.

Escena 2. Singularmente, pues, corresponderá actualizar y ampliar el contenido del Derecho constitucional. Su vinculación con el DIDH resulta inevitable e impostergable. Sin embargo, en este ámbito juega un rol clave el método de inserción y ulterior posición del DIDH en el sistema estatal.

Escena 3. El DIDH genera dos cuestiones en relación con la primacía de la constitución estatal.

Para facilitar la comprensión, denominaré a la primera de ellas «consagración textual». Limitada la observación a América Latina, sus textos constitucionales se distinguen en dos grupos: aquellos en los que existe una concreta y específica

30 Ídem, pág. 193.

31 Ramón Ferreira escribió en 1852 que el Estado tiene como fundamento proporcionar a los hombres medios de conservación y procurar que sean más felices. «Los objetos generales de un buen gobierno son la riqueza, la ilustración, la seguridad de los ciudadanos y la moral pública». V. Ferreira, Ramón, Manual de Derecho Natural (Escrito en 1852 para el Colegio de Tacna en el Perú), ob. cit., págs. 32 y 35 .

Años antes, Thomas Jefferson había escrito también sobre el mismo asunto: «The care of human life and happiness, and not their destruction, is the first and only legitimate object of good government». V. The Writings of Thomas Jefferson, To The Republican Citizens of Washington County, Maryland, Assembled at Hagerstown On the 6th Instant [Monticello, March 31, 1809], vol. VIII, Taylor y Maury, Washington D. C. 1854, pág. 165. Bastaría pensar en el Estado y atribuir un apropiado mundo feliz entre sus finalidades capitales. No obstante, dejo librado al lector la fe y mérito de la afirmación de Jefferson.

32 Popper, Karl R., La sociedad abierta y sus enemigos, ob. cit., pág. 479.

33 Russell, Bertrand, «Lo que creo», en Por qué no soy cristiano, ob. cit., pág. 86. 
«formulación normativa» sobre la vinculación jerárquica entre el DIDH y el Derecho de la constitución, y aquellos textos constitucionales que carecen de enunciados que propicien, expresamente, la aludida referencia. Toda armonía muchas veces resulta peligrosa. En un cuidadoso relato debe escribirse: casi todos los textos constitucionales poseen formulaciones; excepto, por ejemplo, el uruguayo, en el que se encuentra «ausencia de referencia expresa a la interacción entre el DIDH y el Derecho constitucional» ${ }^{34}$.

Una segunda distinción también es iluminativa. Ahora, específicamente, existen cuatro órdenes de escalonamiento jerárquico. En primer lugar, los textos que prescriben la «primacía o prevalencia» del DIDH sobre el Derecho interno de fuente estatal; en segundo lugar, los textos que determinan la «equivalencia» de las ordenaciones normativas, tanto la fuente externa como la estatal; en tercer lugar, las constituciones que determinan que el DIDH se «posicionaría debajo de la propia normatividad constitucional», $y$, por último, el caso de Uruguay, que ante la falta de mención detallada invita al experto o al ciudadano a un «viaje» bastante ilegible y dominado, quizá, por la discreción en la realización del Derecho.

En suma, se aprecia en los Estados latinoamericanos un notorio esfuerzo de los poderes constituyentes. Tolerado o recomendado, el avance progresivo y sustantivo del DIDH configura una nueva ordenación del sistema de fuentes. Ciertamente, cada sistema constitucional posee «determinados rasgos propios de identidad $»^{35}$, aunque muchas veces la prosa desarrollada a nivel textual no alcanza una coherente realización. Los rangos en el orden jurídico son diferentes; no es indiferente la concretización de un doble sistema de fuentes: la propia del Derecho interno del Estado y la internacional. Incluso, se ha llegado a advertir que si la constitución declinase su rango superior, es decir, su específica primacía a favor del DIDH, ello no eliminaría su fuerza normativa. ${ }^{36} \mathrm{El}$ ADN del Derecho internacional se transmite, sin solución de continuidad, en el propio cuerpo del DIDH; así, se contiene la aspiración de prevalencia sobre el derecho interno, incluyendo el constitucional.

Sin embargo, si tuviésemos que elegir por estas horas, preferiría adoptar el mecanismo de la absorción, con un relevante e indisponible margen de apreciación estatal, con rango equivalente y posibilidad de denunciar la salida del sistema internacional. Pese a que la tesis no luzca exagerada u ortodoxamente

34 V. Machado Cyrillo Da Silva, Carolina, «La posición jerárquica del Derecho Internacional de los Derechos humanos en las constituciones sudamericanas», ob. cit., págs. 124-135.

35 V. Dolabjian, Diego A., «Constitución y derechos humanos. 75.22. Modelo para armar», ob. cit., p89-123.

36 V. Bidart Campos, Germán J., El Derecho de la constitución y su fuerza normativa, ob. cit., pág. 456. 
internacionalista, por ahora prefiero observar la casa común, la república, sin pausas y con firmeza, para dar ubicuidad en el espacio, en un futuro cercano, a un Derecho de los derechos humanos para todos los latinoamericanos. Nótese que se trata de una perspectiva fundada «en la insuperable dificultad, hoy existente, de fundar la unidad del ordenamiento en la supremacía del Derecho internacional» ${ }^{37}$; que cesaría, total o parcialmente, acaso, el día que se pueda afirmar la existencia de la completa globalización o mundialización uniforme del Derecho, la existencia de un solo Estado-orden jurídico, y prescindir o devaluar el concepto de Estado que actualmente se maneja. El comentario no deja de ser optimista, porque relega la supremacía total del Derecho internacional a su entronización en la cúspide del orden jurídico, que por entonces dispondría de las instituciones necesarias para crear y realizar un orden jurídico global en el mundo entero. Mientras tanto, los ciudadanos de cada una de las comunidades deben disponer del más certero y adecuado ámbito de libertad para discernir, si acaso, en el futuro toda la aldea sudamericana ${ }^{38}$ se hallaría conglobada por la primacía fundacional de determinadas piezas del DIDH, en plano, rango o nivel distinguidamente superior sobre todo el Derecho; incluido, con propiedad, el propio constitucional de fuente interna.

37 V. Aláez Corral, Benito, «Nacionalidad y ciudadanía ante las exigencias del Estado constitucional», ob. cit., pág. 130.

38 El 22 de junio de 1856, Francisco Bilbao propuso la formación de un Congreso de América del Sur, en el que cada república enviaría igual número de representantes. El Congreso, símbolo de la unión y de la iniciación, se ocuparía, especialmente, en convertir en leyes particulares de cada Estado varias iniciativas, entre las que se destacaron: «... 1. ${ }^{\circ}$ ) La ciudadanía universal. Todo republicano puede ser considerado como ciudadano en cualquier república que habite; $\left.2 .^{\circ}\right)$ Presentar un proyecto de código internacional; $3 .^{\circ}$ ) Un pacto de alianza federal y comercial; $[\ldots .$. $1 .^{\circ} .^{\circ}$ Presentar el plan político de las reformas, en el cual se comprenderán el sistema de contribuciones, la descentralización, y las reformas de la libertad que restituyan a la universalidad de los ciudadanos las funciones que usurpan o han usurpado las constituciones oligárquicas de la América del Sur; $\left[\ldots . .14 .^{\circ}\right.$ ) El Congreso fijará el lugar de su reunión y el tiempo, organizará su presupuesto, creará un diario americano. Es así como creemos que de iniciador se convierta un día en verdadero legislador de la América del Sur; 15..$^{\circ}$ Una vez fijadas las atribuciones unificadoras del Congreso Americano y ratificadas por la unanimidad de las Repúblicas, el Congreso podrá disponer de las fuerzas de los Estados Unidos del Sur, sea para la guerra, sea para las grandes empresas que exige el porvenir de la América; $16^{\circ}$ ) Los gastos que exija la Confederación, serán determinados por el Congreso y repartidos en las Repúblicas a prorrata de sus presupuestos. 17..$^{\circ}$ ) Además de las elecciones federales para representantes del Congreso, puede haber elecciones unitarias de todas las Repúblicas, sea para nombrar un representante de la América, un generalísimo de sus fuerzas, o bien sea para votar las proposiciones universales del Congreso. 18..$^{\circ}$ ) En toda votación general sobre asuntos de la Confederación, la mayoría será la suma de los votos individuales y no la suma de los votos nacionales. Esta medida unirá más los espíritus». V. BILbaO, Francisco: «Iniciativa de la América. Idea de un Congreso Federal de las Repúblicas. Post-dictum», ob. cit. 


\section{FORMULACIÓN Y REPRESENTACIÓN NORMATIVA DE LA REGLA SOBRE LA SUBORDINACIÓN}

\section{VI.1 Estado argentino}

Su Constitución federal (en adelante CF) es el texto más antiguo de los vigentes en América Latina. El 25 de mayo de 1853 el director Provisorio de la Confederación Argentina, Justo José de Urquiza, decretó:

Art. 1. ${ }^{\circ}$ : Téngase por Ley Fundamental en todo el territorio de la Confederación Argentina, la Constitución federal sancionada por el Congreso Constituyente el día primero de mayo de ese año en la Ciudad de Santa Fe. Art. 2: Imprímase y circúlese a los gobiernos de provincia, para que sea promulgada y jurada auténticamente en comicios públicos.

Junto con el decreto, los Gobernadores de Provincia recibieron una nota, también con firma del Director: «... La Constitución política ha sido sancionada...». El artículo 12 del Acuerdo de San Nicolás de los Arroyos imponía al Director Provisorio el deber de promulgar y hacer observar la Constitución luego que fuese sancionada.

Para que esta disposición se lleve a efecto, dispondrá V. E. que se distribuyan ejemplares impresos por los pueblos y territorios de esa provincia, y que en un mismo día se haga en todos los puntos cabeza de partido, una lectura pública de la Constitución, en presencia de las autoridades territoriales [...] Concluida la lectura empezará el acto de juramento [...] encabezado por la fórmula siguiente: «Nosotros, ciudadanos argentinos que formamos el pueblo de la provincia de [...] juramos [...] respetar, obedecer y defender la Constitución política de la Confederación argentina, sancionada por el Congreso General Constituyente el $1 .^{\circ}$ de mayo de $1853^{39}$.

La CF fue jurada el 9 de julio de1853 en toda la Confederación, excepto por el pueblo de la provincia de Buenos Aires, que recién suscribió el pacto constitucional en $1860^{40}$. Posteriormente, el texto fue reformado en los años 1866 , 1898, 1957 y 1994 —el último cambio formalizado-.

39 Ravignani, Emilio, Asambleas Constituyentes Argentinas, t. sexto, 2. ${ }^{\text {a }}$ parte, ob. cit., págs. 837 y 838 .

40 El poder constituyente originario observó ciclo abierto desde 1853 hasta 1860. El ingreso del pueblo de la provincia de Buenos Aires significó un aporte decisivo para la construcción del Estado argentino. Aunque el año «1853» fue un momento clave de la democracia constitucional argentina», debe ser interpretado como «1853-60» dado que, pese a que en este último año lo que hubo fue una reforma, desde el punto de vista jurídico lo que aconteció fue la consolidación del 
Sus enunciados normativos y no normativos se encuentran repartidos en un «Preámbulo», dos «Partes» y las «Disposiciones transitorias». La «Primera Parte» contiene al «Capítulo primero: Declaraciones, derechos y garantías» y al «Capítulo segundo: Nuevos derechos y garantías». La «Segunda Parte: «Autoridades de la Nación» abarca un «Título primero: Gobierno federal» y un «Título segundo: Gobiernos de provincia». Los principios y reglas de naturaleza permanente se alojan en 129 artículos constitucionales, más el «14 bis» (derechos sociales) distribuidos en las dos primeras partes, respectivamente. Por último, las «Disposiciones transitorias» se hospedan en 17 artículos.

Corresponde decir con propiedad que la CF de la Argentina, desde 1853-60, consagra la supremacía normativa de la suma regla y el correspondiente escalonamiento jerárquico de las normas inferiores a ella. Según se alumbra en el artículo 31:

Esta Constitución, las leyes de la Nación que en su consecuencia se dicten por el Congreso y los tratados con las potencias extranjeras son la ley suprema de la Nación; y las autoridades de cada provincia están obligadas a conformarse a ella, no obstante cualquiera disposición en contrario que contengan las leyes o constituciones provinciales, salvo para la provincia de Buenos Aires, los tratados ratificados después del Pacto de 11 de noviembre de 1859.

Por lo tanto, el Derecho de la constitución posee una peculiar forma de ordenar y organizar la vida comunitaria. La subordinación del Estado al Derecho de la CF constituye un mecanismo claro, solvente y riguroso. Además, por su antigüedad, merece ser objeto de una comprensión específica y calificada.

La CF reformada, a partir de 1994, dispone la complementariedad constitucional del DIDH en las condiciones establecidas en el artículo 75, inciso 22, para conjugar el recto entendimiento de la primacía:

Corresponde al Congreso (...) inciso 22: Aprobar o desechar tratados concluidos con las demás naciones y con las organizaciones internacionales y los concordatos con la Santa Sede. Los tratados y concordatos tienen jerarquía superior a las leyes. La Declaración Americana de los Derechos y Deberes del Hombre; la Declaración Universal de Derechos Humanos; la Convención Americana sobre Derechos Humanos; el Pacto Internacional de Derechos Económicos, Sociales y Culturales; el Pacto Internacional de Derechos Civiles y Políticos y su Protocolo Facultativo; la Convención sobre la Prevención y la Sanción del Delito

poder constituyente originario, ciclo abierto en 1853 (en igual sentido, BIDART CAMPOS, Germán J., Tratado elemental de Derecho Constitucional, t. I-A, ob. cit., págs. 476 y ss.). Por eso es correcto mencionar que el texto fundacional argentino es de 1853-60, pese a que en este texto, en general, sólo por razones de simplificación del lenguaje, a veces, se indique «1853», a secas. 
de Genocidio; la Convención Internacional sobre la Eliminación de todas las Formas de Discriminación Racial; la Convención sobre la Eliminación de todas las Formas de Discriminación contra la Mujer; la Convención contra la Tortura y otros Tratos o Penas Crueles, Inhumanos o Degradantes; la Convención sobre los Derechos del Niño; en las condiciones de su vigencia, tienen jerarquía constitucional, no derogan artículo alguno de la primera parte de esta Constitución y deben entenderse complementarios de los derechos y garantías por ella reconocidos. Sólo podrán ser denunciados, en su caso, por el Poder Ejecutivo nacional, previa aprobación de las dos terceras partes de la totalidad de los miembros de cada Cámara. Los demás tratados y convenciones sobre derechos humanos, luego de ser aprobados por el Congreso, requerirán del voto de las dos terceras partes de la totalidad de los miembros de cada Cámara para gozar de la jerarquía constitucional.

A su vez, la ley 24.820 —publicada en el Boletín Oficial (BO) del 29/5/1997- otorgó jerarquía constitucional a la Convención Interamericana sobre Desaparición Forzada de Personas, aprobada por la XXIV Asamblea General de la OEA, en los términos del artículo 75, inciso 22, de la CF. Por su parte, la ley 25778 — publicada en el BO el 3/9/2003 — otorgó jerarquía constitucional a la Convención sobre la Imprescriptibilidad de los Crímenes de Guerra y de los Crímenes de Lesa Humanidad, adoptada por la Asamblea General de la ONU el 26/11/1998 y aprobada por ley 24.584.

La ley 27.044 — publicada en el BO de la República el 22/12/2014— dispuso otorgar jerarquía constitucional en los términos del artículo 75, inciso 22, de la CF, a la Convención sobre los Derechos de las Personas con Discapacidad (ONU). En consecuencia, hoy son catorce los instrumentos del DIDH que gozan de jerarquía constitucional.

Se asume, entonces, que la racional conglobación entre el Derecho (estatal) constitucional y el DIDH (internacional) con jerarquía constitucional, tipificado en la Argentina en términos de equivalencia de las fuentes (CF y DIDH, según regulación contenida en el art. 75 , inc. 22), abre un espacio interesante y de probada riqueza semántica para la «complementariedad», cuyo único requisito reside en el propio margen de reserva estatal propiamente estipulado por la CF. Léase, por ejemplo, un cúmulo de siete argumentos: 1) Por la racionalidad dispuesta para todos los actos de los departamentos que ejercen el poder republicano, según asigna el artículo 28 y reparte a todo el texto constitucional; 2) Por hecho indisputable que «El gobierno federal está obligado a afianzar sus relaciones de paz y comercio con las potencias extranjeras por medio de tratados que estén en conformidad con los principios de Derecho público establecidos en [la] Constitución», según se consigna en el artículo 27 ; 3) por la propia relatividad 
de los derechos constitucionales, todos susceptibles de regulación por el legislador, siempre que no se altere su núcleo; 4) Por la prohibición de otorgamiento de facultades extraordinarias, suma del poder público, sumisiones o supremacías, vinculada en el artículo 29; 5) Por el principio de estricta y máxima juridicidad, reglado en el artículo 19, que establece las competencias delimitadas del poder público; 6) Por la distinción horizontal del poder y la fijación de zonas de reserva a los poderes constituidos, según exigen los artículos 1, 44, 87, 108 y concordantes; 7) por el propio peso del artículo 75 , inciso 22 , al detallar que el DIDH jerarquizado constitucionalmente, en las «condiciones de su vigencia...», no deroga $« . .$. artículo alguno de la primera parte de esta Constitución y deben entenderse complementarios de los derechos y garantías por ella reconocidos». (Huelga destacar que los artículos aludidos por la propia CF a la «Primera parte» albergan, mínimamente, a los contenidos entre los artículos 1 a 33 del texto).

\section{VI.2 Estado brasileño}

El texto vigente fue promulgado el 5 de octubre de $1988 .{ }^{41}$ Consta de un «Preámbulo» y nueve Títulos, con 250 artículos y un larguísimo texto con otros 100 de naturaleza «constitucional transitoria».

En más de cinco lustros, el sistema constitucional originario y fundacional de 1988 se ha reformado en forma reiterada: 88 variaciones, hasta mayo de $2015^{42}$, por intermedio del mecanismo «Emendas» ${ }^{43}$. La abrumadora canti-

${ }^{41}$ El poder constituyente originario de 1988 estipuló, entre las «Disposiciones constitucionales transitorias (ADCT)», un enunciado normativo sumamente original e inédito: art. $2 .^{\circ}$ del ADCT «No dia 7 de setembro de 1993 o eleitorado definirá, através de plebiscito, a forma (república ou monarquia constitucional) e o sistema de governo (parlamentarismo ou presidencialismo) que devem vigorar no País». El plebiscito establecido por el constituyente originario fue reformado por la enmienda Constitucional n. ${ }^{\circ} 2 / 92$, mediante la cual se cambió la fecha de su realización para el 21 de abril de 1993 , y se dispuso que la forma y el sistema de gobiernos definidos por el plebiscito serían vigentes desde el día 1 de enero de 1995. Como resultado del plebiscito, con $66,26 \%$ del total de votos ganó la forma de gobierno república y con 55,58\% ganó el sistema presidencialista.

42 Última enmienda disponible en http://www.planalto.gov.br/ccivil_03/constituicao/Emendas/Emc/emc88.htm.

43 «Art. 60. A Constituição poderá ser emendada mediante proposta: I - de um terço, no mínimo, dos membros da Câmara dos Deputados ou do Senado Federal; II - do Presidente da República; III - de mais da metade das Assembléias Legislativas das unidades da Federação, manifestando-se, cada uma delas, pela maioria relativa de seus membros. $§ 1 .^{\circ}$ A Constituição não poderá ser emendada na vigência de intervenção federal, de estado de defesa ou de estado de sítio. $\S 2 .^{\circ}$ A proposta será discutida e votada em cada Casa do Congresso Nacional, em dois turnos, 
dad de «cambios normativos» puede razonablemente inclinar a pensar que la ideología instituida por el poder constituyente en 1988 sufrió modificaciones; también puede sugerir que la propia vocación jurídica del manifiesto originario se encuentre comprometida por tan radical historicidad que observa las «Emendas». Haya virado o no haya virado desde posturas de intervención del Estado en la economía hacia posturas de fuerte signo diferente, la ley fundamental ha sido mantenida en sus directrices; mejor aún: interpreta un estado de conciencia individuado en la ciudadanía.

Esta estabilidad de los principios generales constitucionales podría reputarse como uno de los elementos que han apoyado el desarrollo y crecimiento de la economía, de las finanzas, de los avances en investigación científica y del propio desarrollo tecnológico que se aprecian en Brasil y sus implicancias en el concierto mundial de Estados. Esta reflexión puede resultar exagerada, aunque el período 1988-2015 es único en la historia del Estado brasileño desde su independencia en 1822. En este sentido, cabe destacar la vigencia ininterrumpida de un texto que, como se ordena en el artículo 1, determina que la República Federativa de Brasil constituye un Estado democrático de Derecho, que tiene como fundamentos la soberanía, la ciudadanía, la dignidad de la persona humana, los valores sociales del trabajo y de la libre iniciativa y el pluralismo político.

En la dogmática brasileña se discute el valor del Preámbulo. Sea o no sea venerable jurídicamente, su simple declaración constituye una manifestación señera sobre la intención de subordinar el orden estatal a los fundamentos de la Constitución:

Nós, representantes do povo brasileiro, reunidos em Assembléia Nacional Constituinte para instituir um Estado Democrático, destinado a assegurar o exercício dos direitos sociais e individuais, a liberdade, a segurança, o bemestar, o desenvolvimento, a igualdade e a justiça como valores supremos de uma sociedade fraterna, pluralista e sem preconceitos, fundada na harmonia social e comprometida, na ordem interna e internacional, com a solução pacífica das controvérsias, promulgamos, sob a proteção de Deus, a seguinte CONSTITUIÇÃO DA REPÚBLICA FEDERATIVA DO BRASIL.

\footnotetext{
considerando-se aprovada se obtiver, em ambos, três quintos dos votos dos respectivos membros. $\S 3 .^{\circ} \mathrm{A}$ emenda à Constituição será promulgada pelas Mesas da Câmara dos Deputados e do Senado Federal, com o respectivo número de ordem. $\S 4$. $^{\circ}$ Não será objeto de deliberação a proposta de emenda tendente a abolir: I - a forma federativa de Estado; II - o voto direto, secreto, universal e periódico; III - a separação dos Poderes; IV - os direitos e garantias individuais. $§ 5 .^{\circ}$ A matéria constante de proposta de emenda rejeitada ou havida por prejudicada não pode ser objeto de nova proposta na mesma sessão legislativa».
} 
A mi juicio, la recta interpretación se encuentra anidada en el propio Preámbulo. Pero para evitar cualquier situación equívoca, el artículo 1 de la Constitución brasileña de 1988 contiene una fórmula normativa parca, concisa y concluyente, en tanto determina la fuente del poder del Estado y su subordinación. Concretamente, en el Parágrafo único se ordena: «Todo o poder emana do povo, que o exerce por meio de representantes eleitos ou diretamente, nos termos desta Constituição» ${ }^{44}$.

Decidida la subordinación al Derecho de la Constitución, restan una palabas relacionadas con el sitial o emplazamiento jurídico del Derecho internacional de los Derechos humanos. En la Constitución de la República Federativa del Brasil del año 1988, se dispuso, originariamente, en el art. 5, LXXCII, § 2.": «Os direitos e garantias expressos nesta Constituição não excluem outros decorrentes do regime e dos princípios por ela adotados, ou dos tratados internacionais em que a República Federativa do Brasil seja parte».

Esta formulación normativa hizo que algunas orientaciones juzgasen la concreción de un sistema de equivalencia o integración de fuentes, en el propio contexto de la Constitución de 1988 y por imperativo de las claves que se pueden inferir de la regla bajo comentario. En cambio, otras orientaciones han sugerido la prevalencia del Derecho constitucional de fuente estatal.

Posteriormente, en 2004, por intermedio de la enmienda constitucional 45/2004, se introdujo el siguiente texto como artículo 5, LXXVIIII, § 3. : «Os tratados e convenções internacionais sobre direitos humanos que forem aprovados, em cada Casa do Congresso Nacional, em dois turnos, por três quintos dos votos dos respectivos membros, serão equivalentes às emendas constitucionais».

Quizá, por de pronto, y ante la escasa actividad registrada en el ámbito propiciado por la propia reforma de 2004 (me refiero al ámbito pergeñado por la nueva formulación contenida en el art. 5, LXXVIII, § 3..$^{\circ}$, corresponda activar la comprensión originaria del sistema de equivalencia o integración de las fuentes.

\section{VI.3 Estado colombiano}

La Constitución colombiana actualmente en vigencia fue promulgada y publicada en la Gaceta constitucional en julio de 1991. Desde entonces ha sido reformada en reiteradas oportunidades (han sido 38, aunque Colombia posee y padece un singular mecanismo de «declaración de inexequibles» de las enmien-

${ }^{44}$ Bunge, Mario A., Diccionario de Filosofía, ob. cit., págs. 213-214. 
das), sin desvanecer ni devaluar las prescripciones originarias de los principios y reglas que la nutren y desarrollan en las 380 piezas de su articulado permanente.

Es preciso destacar que la regla sobre la subordinación se concreta con claridad y concisión en la Constitución política de Colombia de 1991, una de las leyes fundamentales más modernas de la región. Veamos, entonces, los enunciados que, en su conjugación fecunda, programan constitucionalmente la armazón del Estado y su ulterior e inmediata sujeción jurídica al Derecho de la constitución. Más allá de la ductilidad cierta o incierta de la simple declaración, corresponde indicar que desde su Preámbulo se anuncia, sin presuntuosidad pero con vocación normativa, lo siguiente:

El Pueblo de Colombia, en ejercicio de su poder soberano, representado por sus delegatarios a la Asamblea Nacional Constituyente, invocando la protección de Dios, y con el fin de fortalecer la unidad de la Nación y asegurar a sus integrantes la vida, la convivencia, el trabajo, la justicia, la igualdad, el conocimiento, la libertad y la paz, dentro de un marco jurídico, democrático y participativo que garantice un orden político, económico y social justo, y comprometido a impulsar la integración de la comunidad latinoamericana, decreta, sanciona y promulga la siguiente Constitución Política de Colombia.

A su vez, las primeras palabras de las prescripciones constitucionales, precisamente en el artículo 1, se dirigen a ordenar:

Colombia es un Estado social de derecho, organizado en forma de República unitaria, descentralizada, con autonomía de sus entidades territoriales, democrática, participativa y pluralista, fundada en el respeto de la dignidad humana, en el trabajo y la solidaridad de las personas que la integran y en la prevalencia del interés general.

Luego, en el artículo 3 se encuentra una determinación jurídica clave: «La soberanía reside exclusivamente en el pueblo, del cual emana el poder público. El pueblo la ejerce en forma directa o por medio de sus representantes, en los términos que la Constitución establece». Téngase presente que, más adelante, en el artículo 113, se determina taxativamente que «son Ramas del Poder Público, la legislativa, la ejecutiva y la judicial».

Los enunciados referidos dan suficiente cuenta de la idea de constituir un Estado, el origen del poder y el criterio para su ejercicio. La sujeción del Estado al Derecho se encuentra de modo indubitable en las referencias alegadas. Todo cuanto digo contiene, además, un coronamiento expreso en las letras constitucionales colombianas en el artículo 121: «Ninguna autoridad del Estado podrá ejercer funciones distintas de las que le atribuyen la Constitución y la ley». 
El Estado colombiano posee, desde 1991, una de las reglas señeras sobre la cuestión examinada. Concretamente, me refiero al artículo 4 y la materialización normativa de la supremacía constitucional:

La Constitución es norma de normas. En todo caso de incompatibilidad entre la Constitución y la ley u otra norma jurídica, se aplicarán las disposiciones constitucionales. Es deber de los nacionales y de los extranjeros en Colombia acatar la Constitución y las leyes, y respetar y obedecer a las autoridades.

Por de pronto, la originalidad del artículo 4 merece ser resaltada en dos aspectos. En primer lugar, aunque la idea de supremacía constitucional se encuentra en el ideario constitucional de América Latina desde el siglo XIX, la prescripción «La constitución es norma de normas» es novedosa en el vocabulario de los poderes constituyentes. En consecuencia, el artículo 4, al determinar que la Constitución es la norma de mayor jerarquía del sistema, provoca la ordenación jurídica del Estado, porque no puede irse de lo superior a lo inferior sin atravesar las distancias que los separan. Este sencillo ejemplo demuestra la primacía lógica de la constitución.

El segundo aspecto prescrito por el artículo 4 que también posee suficiente originalidad - al menos en el decir propio de los enunciados constitucionalesalude a su acatamiento o deber de obediencia. Toda constitución, como norma ${ }^{45}$,

45 En la sección VII.1, al comentarse la CF de la Argentina, se incluye en la descripción su paradigmático art. 31, creado en 1853. La normatividad del enunciado mencionado se encuentra fuera de debate, merced a su prístina estructura y cotización. En el 2004 la Corte Suprema de Justicia de la Nación declaró en el fallo «Vizzotti» que la CF de la Argentina asume el carácter de una norma jurídica V. «Vizzotti, Carlos A. v. AMSA S. A.», CSJN, Fallos, 327:3677, considerando . $^{\circ}$, suscrito por los jueces Enrique S. Petracchi, Augusto C. Belluscio, Carlos S. Fayt, Antonio Boggiano, Juan C. Maqueda, E. Raúl Zaffaroni y Elena I. Highton de Nolasco, 14/9/2004. Ciertamente, en el art. 31 constitucional se dispuso originariamente en 1853-60 y todavía se encuentra en vigencia: «Esta constitución, las leyes de la Nación que en su consecuencia se dicten por el Congreso y los tratados con las potencias extranjeras son la ley suprema de la Nación...»; sin embargo, a lo largo de la historia fue puesta en jaque, y devaluada y derrotada, la eminente propiedad llamada prescriptividad de la ley, es decir, la determinación de la conducta humana, de ciudadanos y servidores públicos por intermedio de la CF. También, con semejante vocabulario, la fuerza normativa de la constitución es reglada, especialmente, en América Latina. Así, el «sendero colombiano» fue seguido por Venezuela, en 1999, al disponer en el art. 7 de su constitución: «La Constitución es la norma suprema y el fundamento del ordenamiento jurídico...». Ecuador, en 2008, ha dispuesto en su art. 424 constitucional: «La Constitución es la norma suprema y prevalece sobre cualquier otra del ordenamiento jurídico». Análogamente, Bolivia, en 2009, confirma la tendencia hacia la formulación escrita de la normatividad constitucional, en el art. 410, ap. II: «La Constitución es la norma suprema del ordenamiento jurídico boliviano y goza de primacía frente a cualquier otra disposición normativa». 
forma parte del mundo real en cuanto cosa escrita, publicada, acatada. La arquitectura que propone la constitución, como toda norma, tiene un ámbito de su producción y otro ámbito para su realización. Producida la norma, previa comprensión racional, deberá sobrevenir su acatamiento, es decir, su realización tanto por los ciudadanos como por los poderes del Estado. Sin embargo, existen diferentes situaciones en que la realización del Derecho emanado de la constitución exige una interpretación que, específicamente, resultará a cargo de la jurisdicción. La realización del Derecho constitucional será siempre, pues, concreción o ejecución de Derecho creado.

Dispuesta la subordinación del Estado al Derecho de la Constitución Política de 1991, sólo resta indagar la cuestión del espacio jurídico del DIDH, según menciona el propio instrumento en el artículo 93:

Los tratados y convenios internacionales ratificados por el Congreso, que reconocen los derechos humanos y que prohíben en su limitación en los estados de excepción, prevalecen en el orden interno. Los derechos y deberes consagrados en esta Carta, se interpretarán de conformidad con los tratados internacionales sobre derechos humanos ratificados por Colombia.

La aparición de esta regla positiva en el mundo jurídico constitucional de América Latina ha provocado, significativamente, nuevos deslizamientos. Porque ha cambiado el sistema de fuentes, al referirse propiamente sobre la materia la Constitución Política de 1991. De manera decidida el constituyente se inclinó por el criterio de la prevalencia en el «orden interno» del DIDH. No obstante, en el caso de los «derechos y deberes» consagrados por la propia Constitución colombiana de 1991, configura un patrón de interpretación, porque ellos deberán ser interpretados «de conformidad» con los tratados internacionales sobre DDHH ratificados por Colombia. No es objeto de estas líneas hacer una digresión sobre si la Constitución de 1991 debe ser calzada dentro del marco del ámbito referenciado como Derecho interno o no debe ser enmarcada como tal; esto es, si la prevalencia del DIDH se desenvuelve, en todo espacio y tiempo; sin embargo, nótese que la ordenación constituyente por la fórmula «de conformidad» se encuentra lejos de una mera o simplificada referencia; circunstancia que anida, cuando menos, un parámetro para la realización constitucional.

La única dificultad tangible para los ciudadanos y servidores públicos podría reposar en que sea necesaria una previa investigación de campo o determinación empírica para hallar los «tratados y convenciones» que reconocen DDHH y que han sido «distinguidos» con su «ratificación» por el Congreso colombiano. En este sentido, en comparación, el modelo de la Argentina adoptado en 1994, según se ordena en el artículo 75 , inciso 22 — susceptible de ampliación por vía 
congresual-, se presenta como más taxativo que el modelo colombiano, pero su universo puede ser más acotado por su propia autolimitación en la descripción del DIDH que posee jerarquía constitucional (en forma originaria fueron 11 instrumentos; ampliados a 14 por vía congresual).

\section{VI.4 Estado ecuatoriano}

Ecuador ha tenido una gran cantidad de constituciones. Un constitucionalismo agitado. Desde 1830, la entronización misma del Estado ecuatoriano y la configuración republicana independiente, se han sucedido, por lo menos, 15 instrumentos que han tenido diversa suerte.

El texto constitucional vigente en la actualidad fue aprobado en el 2008. En un ejercicio comparativo, por su extensión y detallismo normativo, sólo es superado por la Constitución de Brasil. No es una cuestión que carezca de significación, en la inteligencia de que la población y el territorio, respectivamente, de México, la Argentina y Colombia, resultan superiores a los del Ecuador. Con evidencia, el poder constituyente ha necesitado disponer la reglamentación y enunciar normas constitucionales que, por su configuración y emplazamiento, se encuentren fuere de los ámbitos cotidianos de deliberación política comunitaria.

En su «Preámbulo» reúne la celebración a la Pacha Mama y la formulación de «una nueva forma de convivencia ciudadana, en diversidad y armonía con la naturaleza, para alcanzar el buen vivir, el sumak kawsay». Luego, los enunciados constitucionales se ordenan en 9 «Títulos» y, exactamente, 444 artículos para dar residencia a la variada gama de principios y reglas de naturaleza permanente. Posee también 30 «Disposiciones transitorias», una «Disposición derogatoria»; un «Régimen de transición» compuesto por 30 artículos, y una «Disposición final: «Esta Constitución, aprobada en referéndum por el pueblo ecuatoriano, entrará en vigencia el día de su publicación en el Registro oficial» ${ }^{46}$.

La definición sobre el modelo de Estado elegido no se hace esperar. Las primeras letras prescriptivas se orientan hacia allí; en efecto, en el artículo 1 se dispone:

El Ecuador es un Estado constitucional de derechos y justicia, social, democrático, soberano, independiente, unitario, intercultural, plurinacional y laico. Se organiza en forma de república y se gobierna de manera descentralizada.

La soberanía radica en el pueblo, cuya voluntad es el fundamento de la autoridad, y se ejerce a través de los órganos del poder público y de las formas de participación directa previstas en la Constitución.

46 Concretada el 20 de octubre de 2008. 
La génesis del poder y el sometimiento de éste a los marcos constitucionales operan de modo claro y solvente, al menos según surge del artículo 1 constitucional. Desde la misma regla, en clave normativa, corresponde inferir que el poder del Estado en Ecuador nace y se sostiene en el poder individuado en cada uno de los ciudadanos que integran su pueblo. La soberanía de los ciudadanos que integran el pueblo es el fundamento del poder del Estado, porque sin ella resulta inimaginable e irrepresentable el desenvolvimiento de los diferentes círculos que contiene la vida comunitaria. La configuración del Estado constitucional queda a cargo del Derecho de la constitución. Su existencia jurídica, por ende, apropiada, única y exclusivamente puede encontrar fundamento de derivación más que en la Constitución de 2008. Pareciera atinado decir que Estado y Derecho constitucional se encuentran unidos de modo indisoluble; quizá, en forma semejante que un ser vivo y su propia ordenación y correspondiente organización.

Otro aspecto interesante, en cuanto a la regla de subordinación bajo análisis, consiste en determinar que la Constitución ecuatoriana, en el Estado constitucional, es la fuente del Derecho por antonomasia. Así se dispone en el artículo 424:

La Constitución es la norma suprema y prevalece sobre cualquier otra del ordenamiento jurídico. Las normas y los actos del poder público deberán mantener conformidad con las disposiciones constitucionales; en caso contrario carecerán de eficacia jurídica.

La subordinación al régimen imperativo de la Constitución 2008 se ratifica en el artículo 426: «Todas las personas, autoridades e instituciones están sujetas a la Constitución».

Naturalmente, la regla sobre la subordinación del Estado al Derecho de la constitución también requiere la franca explicitación del escalonamiento o gradación de los enunciados que integran el orden estatal.

Art. 425. El orden jerárquico de aplicación de las normas será el siguiente: La Constitución; los tratados y convenios internacionales; las leyes orgánicas; las leyes ordinarias; las normas regionales y las ordenanzas distritales; los decretos y reglamentos; las ordenanzas; los acuerdos y las resoluciones; y los demás actos y decisiones de los poderes públicos. En caso de conflicto entre normas de distinta jerarquía, la Corte Constitucional, las juezas y jueces, autoridades administrativas y servidoras y servidores públicos, lo resolverán mediante la aplicación de la norma jerárquica superior. La jerarquía normativa considerará, en lo que corresponda, el principio de competencia, en especial la titularidad de las competencias exclusivas de los gobiernos autónomos descentralizados. 
Sobre el constitucionalismo global, esto es, el DIDH, en la segunda parte del artículo 424 se instituye lo siguiente:

La Constitución y los tratados internacionales de derechos humanos ratificados por el Estado que reconozcan derechos más favorables a los contenidos en la Constitución, prevalecerán sobre cualquier otra norma jurídica o acto del poder público.

No obstante, resulta sugestivo que la prescripción contenida en el artículo 425 no colabora, precisamente, en la tarea de determinar la «equivalencia de las fuentes», porque allí se lee:

«El orden jerárquico de aplicación de las normas será el siguiente: La Constitución; los tratados y convenios internacionales...»

Significativamente, el «punto y coma» luego de «Constitución» tendrá que ser armonizado con la inteligencia también dichosa provista por el artículo 424 de la misma estatura constituyente.

Para salvar cierta discordia normativa — que podría haber sido evitada, ante tanta profusión-, será necesario volcar la recta interpretación hacia la segunda parte del artículo 426:

Los derechos consagrados en la Constitución y los instrumentos internacionales de derechos humanos serán de inmediato cumplimiento y aplicación. No podrá alegarse falta de ley o desconocimiento de las normas para justificar la vulneración de los derechos y garantías establecidos en la Constitución, para desechar la acción interpuesta en su defensa, ni para negar el reconocimiento de tales derechos.

En consecuencia, correspondería opinar que el poder constituyente ecuatoriano en 2008 optó por el sistema de equivalencia de las fuentes, en la inteligencia provista por la segunda parte del artículo 424, que se coordina con el artículo 426 recién citado.

Pareciera, pues, que la equivalencia de las fuentes operaría a condición de que reconozcan derechos más favorables a los contenidos en la Constitución. Ciertamente, se trata de un criterio constituyente razonable, pero del que no se puede predicar la adopción de un modelo de equivalencia en sentido estricto.

La Constitución del Ecuador de 2008, en términos jurídicos, posee interesantes novedades, algunas de ellas han sido referidas más arriba. Otras, como por ejemplo la contenida en el artículo $95^{47}$, revelan una manifiesta intención de

47 «Art. 95. Las ciudadanas y ciudadanos, en forma individual y colectiva, participarán de manera protagónica en la toma de decisiones, planificación y gestión de los asuntos públicos, y en 
construir el orden estatal desde una perspectiva más ancha y sobresaliente que la ensayada por el constitucionalismo liberal sólo preocupado por la esfera de libertad del individuo. La realización concreta del modelo pondrá de manifiesto el grado de protagonismo ciudadano en la configuración del orden alentado por la Constitución ecuatoriana.

En definitiva, la Constitución de la República del Ecuador de 2008 subordina al orden estatal. La estatura de sus enunciados asegura esta afirmación; al mismo tiempo, el DIDH, en las condiciones descritas arriba, también integra el escenario de más alta estirpe jurídica. ${ }^{48}$

\section{VI.5 Estado mexicano}

La Constitución Política de los Estados Unidos Mexicanos entró en vigor en 1917. En pocos meses celebrará sus primeros 100 años. Su antigüedad es

el control popular de las instituciones del Estado y la sociedad, y de sus representantes, en un proceso permanente de construcción del poder ciudadano. La participación se orientará por los principios de igualdad, autonomía, deliberación pública, respeto a la diferencia, control popular, solidaridad e interculturalidad. La participación de la ciudadanía en todos los asuntos de interés público es un derecho, que se ejercerá a través de los mecanismos de la democracia representativa, directa y comunitaria».

48 El asunto no queda agotado ni clausurado; mejor aún: se encuentra abierto a debate. Ciertamente, al tratarse de una ley fundamental moderna y ambiciosa, llama la atención las dificultades que se observan en la configuración estrictamente normativa. No puedo desconocer la presencia del art. 438: "La Corte Constitucional emitirá dictamen previo y vinculante de constitucionalidad en los siguientes casos, además de los que determine la ley: 1. Tratados internacionales, previamente a su ratificación por parte de la Asamblea Nacional». Por ende, una posibilidad interpretativa sería la siguiente, en armonía con lo sustentado en el cuerpo principal de este escrito. Así, la Constitución del Ecuador y los instrumentos del DIDH «ya ratificados» (art. 424) tienen la misma jerarquía constitucional; lo cual no descartaría que el DIDH «por ratificar» (art. 438) sea considerado con una jerarquía infraconstitucional en cuanto están sujetos a control previo de constitucionalidad. Ahora bien, en rigor de verdad, sólo cabría hablar de jerarquía entre normas vigentes. De tal modo, no cabría hablar de jerarquía infraconstitucional de los DIDH «por ratificar» frente a la Constitución pues, simplemente, no están vigentes todavía. En cambio, sí tiene sentido hablar de jerarquía de los instrumentos del DIDH «ya ratificados» respecto de la Constitución; la cual, en el caso, sería idéntica o semejante. Mantengo, pues, la idea de que el constituyente ecuatoriano adoptó un sistema de equivalencia jerárquica entre la Constitución y el DIDH ya ratificado. Debo repetir: no ha sido la mejor redacción de las fórmulas normativas, porque, pese a la abundancia de reglas, no es fácil compaginar la realización armónica preferida por los asambleístas reunidos en Montecristi a juzgar por la ausencia de concisión y la atomización de diversos criterios que no siempre son coincidentes. Por último, la propia denominación del Título IX: «Supremacía de la Constitución» (que comprende arts. 424 a 444), hasta podría hospedar la idea de la cotización infraconstitucional del DIDH. 
solamente superada por los 162 años del texto fundacional del Estado argentino. Sin embargo, la Constitución mexicana ha sido reformada en 223 ocasiones, mientras que durante ese mismo período (1917-2015) la CF argentina ha sido reformada apenas en tres oportunidades, y una de las reformas - 1949— fue dejada sin efecto.

En México, la regla sobre la variación observa una gran utilización ${ }^{49}$. Cabe señalar que los cambios constitucionales han sido heterogéneos, porque mantienen diferente alcance. Quizá haya predominado la idea de que la constitución es una entidad mundana; y por tanto, no debe ser ídolo de ilustración ni ser juzgada como el producto inalcanzable de personas sabias o no sabias, que en su mayoría han muerto. No obstante, la intensidad y la profundidad de los propios cambios no autorizan a juzgar aquí si ha sucedido o no ha sucedido la pérdida del material normativo originario, o todo ha consistido en un desarrollo jurídico que ha permitido la manutención global de la arquitectura constitucional asumida en Querétaro hace casi un siglo. Todo se despliega en 136 artículos, a los que corresponde añadir una variopinta colección de «Artículos transitorios».

El texto original de la Constitución mexicana de 1917 da carta de ciudadanía normativa a robustos aspectos sociales; así, por ejemplo, las reglas sobre educación (art. 3); la determinación de que la propiedad de las tierras y aguas comprendidas dentro de los límites del territorio nacional corresponde originariamente al Estado; así como el derecho del Estado de imponer en todo tiempo a la propiedad privada «las modalidades que dicte el interés público». Probablemente, el ícono normativo lo configure el Título Sexto: «Del Trabajo y de la Previsión Social», porque se destinan, por primera vez en América Latina, alrededor de 2.000 palabras (todo en su solo artículo, el 123) para formular con estatura constitucional un verdadero código de la cuestión social: duración de la jornada laboral; vacaciones; minoridad; trabajo de mujeres; salario; igualdad de salario a igual trabajo, etcétera.

En cuanto a la subordinación jurídica del Estado, se concreta del siguiente modo, según el artículo 39:

La soberanía nacional reside esencial y originariamente en el pueblo. Todo poder público dimana del pueblo y se instituye para beneficio de éste. El pueblo tiene en todo tiempo el inalienable derecho de alterar o modificar la forma de su gobierno.

49 Brasil tiene un promedio de poco más de tres enmiendas por año; México se acerca a dicha dimensión y Colombia se mantiene cerca de dos reformas, si se intentase vincular con un promedio el sesgo del cambio constitucional; la Argentina ha aguardado, con la misma lógica, más de 32 años para cambiar reglas de su constitución. 
A continuación, en el artículo 40 se instaura con propiedad la determinación que obliga al Derecho de la constitución.

Es voluntad del pueblo mexicano constituirse en una República representativa, democrática, laica, federal, compuesta de Estados libres y soberanos en todo lo concerniente a su régimen interior; pero unidos en una federación establecida según los principios de esta ley fundamental.

La gradación jurídica se contempla en el artículo 113. Allí queda claro que la Constitución mexicana es el fundamento del Estado.

Esta Constitución, las leyes del Congreso de la Unión que emanen de ella y todos los Tratados que estén de acuerdo con la misma, celebrados y que se celebren por el Presidente de la República, con aprobación del Senado, serán la Ley Suprema de toda la Unión. Los jueces de cada Estado se arreglarán a dicha Constitución, leyes y tratados, a pesar de las disposiciones en contrario que pueda haber en las Constituciones o leyes de los Estados.

La supremacía al orden constitucional, como se leerá más abajo, asume una nueva vertiente a partir de 2011, fruto de la validación del DIDH, y no ha sido afectada. La base del orden jurídico estatal, por lo demás, se encuentra fuera de debate ante la genuina y clara disposición reguladora contenida en el artículo 113 recién referenciado.

La Constitución mexicana contiene desde 1917 una regla sumamente original para el tiempo de su redacción, puesto que luego ha sido imitada por muchos Estados. Dedica el título Noveno a la «Inviolabilidad de la Constitución», donde por intermedio del artículo 136 se dispuso:

Esta Constitución no perderá su fuerza y vigor, aun cuando por alguna rebelión se interrumpa su observancia. En caso de que por cualquier trastorno público, se establezca un gobierno contrario a los principios que ella sanciona, tan luego como el pueblo recobre su libertad, se restablecerá su observancia, y con arreglo a ella y a las leyes que en su virtud se hubieren expedido, serán juzgados, así los que hubieren figurado en el gobierno emanado de la rebelión, como los que hubieren cooperado a ésta.

Se trata de una regla semejante a una determinación de «clausura» ${ }^{50}$ del orden instaurado; es decir, una regla que presupone la existencia de un proceso de decisión para identificar las consecuencias normativas del sistema y descalifi-

${ }^{50}$ V. Alchourrón, Carlos, y Bulygin, Eugenio, Introducción a la metodología de las ciencias jurídicas y sociales, ob. cit., págs. 189-196. 
car todas aquellas acciones que no se encuentran calificadas por el orden constitucional.

Desde 2011 se ha operado un relevante cambio en México, en el orden autorizado por su Constitución, en cuanto a una definición explícita sobre el ámbito del DIDH. Más allá del acierto o deficiencia que pueda hallarse o no hallarse en la propia formulación normativa, con seguridad se afirma que el sitio para emplazar este tipo de reglas lo constituye, sin dudas, el artículo 1 de cualquier articulación constitucional. Así lo hacen saber los mexicanos:

En los Estados Unidos Mexicanos todas las personas gozarán de los derechos humanos reconocidos en esta Constitución y en los tratados internacionales de los que el Estado Mexicano sea parte, así como de las garantías para su protección, cuyo ejercicio no podrá restringirse ni suspenderse, salvo en los casos y bajo las condiciones que esta Constitución establece.

Las normas relativas a los derechos humanos se interpretarán de conformidad con esta Constitución y con los tratados internacionales de la materia favoreciendo en todo tiempo a las personas la protección más amplia.

Todas las autoridades, en el ámbito de sus competencias, tienen la obligación de promover, respetar, proteger y garantizar los derechos humanos de conformidad con los principios de universalidad, interdependencia, indivisibilidad y progresividad. En consecuencia, el Estado deberá prevenir, investigar, sancionar y reparar las violaciones a los derechos humanos, en los términos que establezca la ley ${ }^{51}$.

Ha de ser cierto que el Estado mexicano ha optado por un sistema de equivalencia de fuentes, en materia de DIDH. Además, favorecer a las personas en todo tiempo la protección más amplia elimina la posibilidad de pensar en algún matiz depredador o limitante del criterio de equivalencia adoptado.

\section{COMENTARIOS FINALES}

Primero. El Estado, el Derecho y la constitución son entes artificiales; naturalmente, también lo es la asociación que da lugar a la mancomunidad: «Estado constitucional». El orden natural, si acaso fuese tal, no requiere procesos de control, pero puede producir, ciertamente, situaciones de encantamiento al espectador o a quien realice o intente su compresión. Por el contrario, el orden social, inventado por el hombre, sí requiere procesos de control. Sin embargo,

${ }^{51}$ Compárese la diferencia en la redacción con la referencia semejante contenida en el art. 93, primer párrafo, de la Constitución de Colombia. V. Sección VII.3. 
las ordenaciones fundamentales desarrolladas por los artificios para el control social creados por él no deberían producir encantamiento acrítico, porque al no ser objetos naturales siempre reflejan una serie de relaciones de fuerza en constante cambio. Identificar la desigualdad de los hombres reviste tarea prioritaria en el examen del origen y desarrollo del Estado constitucional.

Segundo. El artificio constitucional constituye el cuarto elemento del Estado. Se ilustra un enfoque original: la conexión de la constitución con el ente que fundamenta, el Estado. En el Estado ordenado u organizado con fundamentos en una constitución, su constitucionalización nunca es cabal ni totalizadora.

Tercero. Las reglas constitucionales que fundamentan al mencionado Estado prescriben con bastante suficiencia la subordinación certera de su orden jurídico, la autorización detallada para su cambio formalizado, la distinción de las funciones controladas de sus poderes gubernativos y notable literatura sobre la acción de sus derechos fundamentales; baste señalar, por ahora, que la descripción constituye el resultado de una previa comprensión analítica, que guarda para cada regla un rasgo básico o manifestación preferencial de su entidad propia.

Cuarto. La Constitución, al fijar determinados procedimientos, cumpliría la función responsable de la más alta alcurnia atribuible a las formas jurídicas: alentar la paz. La regla sobre la subordinación está llamada a desarrollar un rol eminentemente procesal, porque la tensión entre individuo y Estado, el conflicto entre ciudadano y autoridad, imposible de resolver con rasgos definitivos, se disuelve a favor de ciertos procedimientos específicos. Recuérdese al respecto que, al subordinar la actuación estatal al Derecho de la constitución, dichos procesos confían el arraigo de determinada certeza. La naturaleza procesal queda fijamente establecida con la regla sobre la subordinación.

En los cinco Estados cuya arquitectura fundamental aquí se evalúa, la soberanía de la vida comunitaria se dispone por intermedio de una norma constitucional escrita. La concreción de la regla sobre la subordinación, entendida desde sus formulaciones normativas, resulta una verdad indisputable. Sin temor a equivocarme, dicha tesis podría extenderse al conjunto de los Estados que integran América Latina, aunque en algunos casos con matices, porque la distancia entre idealidad constituyente y realidad político-constitucional asume tal relevancia que produce una devaluación de la regla sobre la subordinación del Estado al Derecho.

Quinto. El Estado constitucional, en especial en América Latina, quizá signifique una ideación infinitamente más potente que su apropiada concreción en la realidad política y comunitaria, ya que la distancia entre idealidad constituyente y realidad política asume un grado significativo. Hace años se ha dicho que una «constitución no hace en absoluto a un Estado, salvo en la más estricta 
significación literal, un auténtico Estado constitucional» ${ }^{52}$. En ninguna de las líneas anteriores apelé al juego de palabras, porque juzgo relevante la cruda descripción, sin la complaciente veneración en que incurren ciertos intérpretes que creen posible un inexistente culto oficial a la constitución, olvidando la más genuina posibilidad entregada por la sociedad abierta: o todos realizamos el Derecho constitucional, o el Derecho constitucional es simplemente una nueva forma arbitraria e irracional de dominación. Tampoco ahora jugaré con las palabras. Bastará, por eso y para finalizar, una afirmación, con igual pureza teórica que la perseguida en la sección III: sin constitución, no hay Estado constitucional. La subordinación jurídica del Estado al Derecho de la constitución, por de pronto, fomenta la ilusión de que los ciudadanos sean efectivamente iguales en libertad y el poder constituido constituya una zona de competencias limitadas sometidas al control racional. Hasta hoy, el ideal del Estado constitucional es la mejor herramienta inventada por el hombre para vivir en comunidad y no tiene rival...

\section{BIBLIOGRAFÍA}

Entre las fuentes que más serviciales me han sido, menciono las siguientes:

Alchourrón, Carlos y Bulygin, Eugenio (1998). Introducción a la metodología de las ciencias jurídicas y sociales (Buenos Aires, Astrea).

Alberdi, Juan B. (1852). Bases y puntos de partida para la organización política de la República Arjentina, derivados de la lei que preside al desarrollo de la civilización en

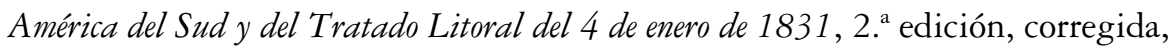
aumentada de muchos párrafos y un proyecto de constitución, concebidos según las bases propuestas por el autor (Valparaíso, Chile, Imprenta del Mercurio, Santos Tornero y Cía.).

BARCESAT, Eduardo (2015). «Deber de obediencia a la supremacía de la Constitución», en «A veinte años de la Reforma Constitucional. Examen y perspectiva», págs. 36-38, en Revista de Derecho Público, n. 9 (Buenos Aires, Ministerio de Justicia y Derechos Humanos, Presidencia de la Nación).

Barroso, Luis Roberto (2012). Curso de Direito Constitucional Contemporâneo. Os conceitos fundamentais e a construção do novo modelo (San Pablo, Saraiva).

Bidart CAmpos, Germán J. (1995). El Derecho de la constitución y su fuerza normativa (Buenos Aires, Ediar).

- (1996). Manual de la constitución reformada (Buenos Aires, Ediar).

52 Loewenstein, Karl, Teoría de la constitución, ob. cit., pág. 161. 
- (1999-2000). Tratado elemental de Derecho constitucional, t. I-A, ed. act. y amp. (Buenos Aires, Ediar).

BogDANDY, Armin von (2013). «Ius constitutionale commune latinoamericanum. Una aclaración conceptual desde una perspectiva europea», en Luis Raúl González Pérez y Diego Valadés (coords.), El constitucionalismo contemporáneo. Homenaje a Jorge Carpizo (México, D. F., IIJ, UNAM).

Bonavides, Paulo (2014). Del Estado liberal al Estado social (trad. M. Méndez Rocasolano y supervisión académica de R. Rabinovich-Berkman, Buenos Aires, Astrea).

- (2011). Curso de Direito constitucional, 26. ${ }^{\text {a }}$ ed. (São Paulo, Malheiro Editores).

Bourdieu, Pierre (2014). Sobre el Estado. Cursos en el Collège de France (1989 1992) (trad. P. González Rodríguez, Barcelona, Anagrama).

CARPIZO, Jorge (2005). «Derecho constitucional latinoamericano y comparado», en Boletín Mexicano de Derecho Comparado, nueva serie, año XXXVIII, n. ${ }^{\circ} 114$, UNAM, septiembre-diciembre.

CONDORCET (2004). Bosquejo de un cuadro bistórico de los progresos del espíritu bumano (introducción y traducción revisada por A. Torres del Moral, Madrid, CEPC).

Correa, Rafael (2014). Ecuador: de Banana Republic a la no república (Colombia, Debolsillo).

Corwin, Edward S. (1936). «The Constitution as Instrument and as Symbol», The American Political Science Review, Vol. 30, n. ${ }^{\circ}$ 6, American Political Science Association, págs. 1071-1085.

De Vergottini, Giuseppe (2005). Derecho constitucional comparado (trad. C. Herrera, Buenos Aires, Universidad).

Dolabjian, Diego A. (2013). «Constitución y derechos humanos. 75.22. Modelo para armar», en Contextos, publicación del Seminario sobre Derecho Público de la Defensoría del Pueblo de la Ciudad de Buenos Aires, n. ${ }^{\circ} 5$, págs. 89-123.

Ekmekdjian, Miguel Á. (1993). Tratado de Derecho constitucional, t. I (Buenos Aires, Depalma).

Ferrajoli, Luigi (2012). «Constitucionalismo garantista y constitucionalismo principialista», en $U n$ debate sobre el constitucionalismo, págs. 11-50 (trad. N. Guzmán, Madrid, Marcial Pons).

Ferreira Mendes, Gilmar (2009). «La construcción de un Derecho común iberoamericano. Consideraciones en homenaje a la doctrina de Peter Häberle y su influencia en Brasil», en Revista de Derecho constitucional europeo, n. ${ }^{\circ} 11$, págs. 65-86 (trad. M. Rodrigues Canotilho, Granada, Departamento de Derecho constitucional, Universidad de Granada).

García-Herreros, Orlando (2011). Apuntes de Derecho constitucional colombiano (Bogotá, Universidad Sergio Arboleda). 
Gargarella, Roberto (2012). 200 años de constitucionalismo en América Latina 1810-2010 (Buenos Aires, copia del manuscrito original gentilmente cedido por su autor y existente en mi archivo personal).

- (2014). La sala de máquinas de la constitución. Dos siglos de constitucionalismo en América Latina 1810-2010 (Buenos Aires, Katz).

HäBERLE, Peter (2003). «La constitución en el contexto», AIJC, CEPC, Madrid, n. ${ }^{\circ} 7$.

- (2003). El Estado constitucional (estudio introductorio de Diego Valadés, trad. H. Fix-Fierro, México, D. F., IIJ).

LAPORTA, Francisco (2014). «Gobernanza y soft law: nuevos perfiles jurídicos de la sociedad internacional», en A. Ruiz Miguel (ed.), Entre Estado y Cosmópolis Derecho y justicia en un mundo global (Madrid, Trotta).

Loewenstein, Karl (1979). Teoría de la constitución (trad. A. Gallego Anabitarte, Barcelona, Ariel).

Machado Cyrillo Da Silva, Carolina (2013). «La posición jerárquica del Derecho Internacional de los Derechos humanos en las constituciones sudamericanas», en Contextos, publicación del Seminario sobre Derecho Público de la Defensoría del Pueblo de la Ciudad de Buenos Aires, n. ${ }^{\circ}$.

MARquardt, Bernd (2011). Los dos siglos del Estado constitucional en América Latina (1810-2010). Historia constitucional comparada, tomo $11810-1880$ y tomo 2 1880-2010 (Universidad Nacional de Colombia).

Ravignani, Emilio (1939). Asambleas Constituyentes Argentinas, t. sexto, 2. ${ }^{a}$ parte (Buenos Aires, Peuser).

RosatTi, Horacio Daniel (1994). Tratado de Derecho constitucional, t. I (Buenos Aires, Rubinzal-Culzoni).

- (2011). Tratado de Derecho constitucional, t. II (Buenos Aires, Rubinzal-Culzoni).

Ruiz Miguel, Alfonso (2014). «La función del Derecho en un mundo global», en Entre Estado y Cosmópolis. Derecho y justicia en un mundo global (Madrid, Trotta).

Russell, Bertrand (1960). El poder en los hombres y en los pueblos (trad. L. Echávarri, Buenos Aires, Losada).

- (2004): «Lo que creo», en Por qué no soy cristiano (Barcelona, Edhasa).

SAgüÉs, Néstor (2004). Teoría de la constitución (Buenos Aires, Astrea).

Salazar Ugarte, Pedro (2013). «El nuevo constitucionalismo latinoamericano (una perspectiva crítica)», en Luis Raúl González Pérez y Diego Valadés (coords.), El constitucionalismo contemporáneo. Homenaje a Jorge Carpizo (México, D F., IIJ, UNAM).

SÁNCHEZ Viamonte, Carlos (1967). «Constitucionalismo», en Enciclopedia Jurídica Omeba, t. III (Buenos Aires, Editorial Bibliográfica).

Schmitт, Carl (2014). El valor del Estado y el significado del individuo (trad. C. Pardo, Madrid, CEPC). 
Service, Elman R. (1984). Los orígenes del Estado y de la civilización (trad. M. Carmen Ruiz de Elvira Hidalgo, Madrid, Alianza).

Torres del Moral, Antonio (2004). Principios de Derecho constitucional español (Madrid, Universidad Complutense de Madrid)

Tushnet, Mark (2009). «The Inevitable Globalization of Constitutional Law», en Virginia Journal of International Law, Vol. 50, Issue 1, págs. 985-1006.

VAladés, Diego (2011). «Visión panorámica del constitucionalismo del Siglo XX», en Revista Latinoamericana de Estudos constitucionais, n. 12 (Fortaleza, Demócrito Rocha).

Vargas Llosa, Mario (2005). Diccionario de América Latina (Barcelona, Paidós).

Ventura, Deisy (2005). Las asimetrías entre el Mercosur y la Unión Europea. Los desafíos de una asociación interregional (Montevideo, Fundación Konrad Adenauer).

Zaffaroni, E. Raúl (2012). «Ciudadanía y jurisdicción en América Latina», en Contextos, n. 4 (Buenos Aires, Seminario de Derecho Público de la Defensoría del Pueblo de la Ciudad de Buenos Aires).

- (s/f). El Derecho latinoamericano en la fase superior del colonialismo (en prensa, original gentilmente cedido por el autor).

Title:

THE RULE OF SUBORDINATION AS FOUNDATION OF THE CONSTITUTIONAL STATE. ITS REGULATION IN ARGENTINA, BRAZIL, COLOMBIA, ECUADOR AND MEXICO.

\begin{abstract}
:
Llamase Estado constitucional al ente fundado en una constitución, instrumento que persigue la convivencia pacífica de los ciudadanos y/o control responsable de la paz. Las reglas que lo fundamentan prescriben su subordinación al ordenamiento, la autorización para la reforma del orden, la distinción de las funciones controladas de sus poderes gubernativos y notable literatura sobre la acción de los derechos fundamentales. Peculiarmente, la regla sobre la subordinación persigue establecer la certeza, es decir, el «conocimiento seguro» por parte de la ciudadanía y los servidores públicos del campo dominado por el Derecho, que por ser general y normativo, posibilita una comunidad de ciudadanos igualmente libres, con abierta intención de excluir la
\end{abstract}


arbitrariedad. Se analiza su despliegue y formulación normativa en los Estados citados en el título ${ }^{53}$.

\begin{abstract}
A constitutional State is the entity based on a constitution, an instrument aimed at attaining the peaceful coexistence of citizens and/ or the responsible control of peace. The rules that serve as foundation of the State prescribe the State's subordination to the legal order, the need of authorization to reform the order, the distinction between the controlled functions of the branches of Government, and distinguished provisions on the operation of basic rights.

Specifically, the subordination rule is aimed at establishing certainty, i.e. the «certain knowledge» by citizens and public servants of the field governed by the Law which, being general and normative, guarantees a community of equally-free citizens, with an open intent to exclude arbitrariness. This work goes into the deployment and normative design of the subordination rule in the nations mentioned in the title.
\end{abstract}

\title{
Palabras clave.
}

América Latina. Estado constitucional. Reglas que fundamentan al Estado. Regla sobre la subordinación y positividad del Derecho de la constitución. Normatividad de la constitución. Jerarquía del Derecho internacional de los Derechos humanos

\section{Summary}

I. Introduction. II. Argumentative Strategy. III. Theoretical Framework. IV. Constitution-Fourth Element of the State. V. Constitutional Rules. VI. Subordination Rule. VII. Normative Design and Representation of the Subordination Rule. VII.1 Argentina. VII.2 Brazil. VII.3 Colombia. VII.4 Ecuador. VII.5 Mexico. VIII. Final Comments.

53 El autor agradece los aportes de Carolina Machado Cyrillo Da Silva, Johanna M. Romero, Ricardo Garzón Cárdenas, Edgar Fuentes Contreras, José Eduardo Schuh, Diego Dolabjian, Fernanda Lage, Leandro A. Martínez, M. Alejandra Perícola, M. Fernanda Lombardo, Mario F. Cámpora, Gustavo Alejandro Szarangowicz, Sebastián Toledo, Ricardo Rabinovich Berkman, Leandro Vergara, Enrique Javier Morales, Leandro E. Ferreyra, Mariano Vitetta, Diego Valadés y E. Raúl Zaffaroni. 


\section{Keywords}

Latin America. Constitutional State. Rules supporting the State. Rule of subordination and positive nature of the law of the constitution. Normative nature of the constitution. Ranking of International Human Rights Law. 
